Advant age of et hanol $f$ uel for gas gener at or cycle ai $r$ turbo $r a m i$ et engi ne

\begin{tabular}{|l|l|}
\hline 著者 & M NATO Ryoj i ro \\
\hline $\begin{array}{l}\text { j our nal or } \\
\text { publ i cat } \mathrm{i} \text { on } \mathrm{t} \text { i t I e }\end{array}$ & Aer ospace Sci ence and Technol ogy \\
\hline vol une & 50 \\
\hline page r ange & $161-172$ \\
\hline year & $2016-03$ \\
\hline URL & ht t p: //hdl . handl e. net /10258/00008626 \\
\hline
\end{tabular}


Advant age of et hanol $f$ uel for gas gener at or cycle ai $r$ turbo $r a m i$ et engi ne

\begin{tabular}{|l|l|}
\hline 著者 & M NATO Ryoj i ro \\
\hline $\begin{array}{l}\text { j our nal or } \\
\text { publ i cat } \mathrm{i} \text { on } \mathrm{t} \text { i t I e }\end{array}$ & Aer ospace Sci ence and Technol ogy \\
\hline vol une & 50 \\
\hline page r ange & $161-172$ \\
\hline year & $2016-03$ \\
\hline URL & ht t p: //hdl . handl e. net /10258/00008626 \\
\hline
\end{tabular}




\title{
Advantage of Ethanol fuel for Gas Generator Cycle Air Turbo
}

\section{Ramjet Engine}

\author{
Ryojiro Minato ${ }^{1 *}$ \\ ${ }^{1}$ Department of Mechanical and Aerospace Engineering, Muroran Institute of Technology., \\ 27-1 Mizumoto-cho, Muroran, Hokkaido, Japan, 050-8585 \\ * Corresponding Author \\ TEL/FAX : $\quad+81-143-46-5378$ \\ E:mail : $\quad$ r-minato@mmm.muroran-it.ac.jp
}

\begin{abstract}
Performance analyses of Gas Generator cycle Air Turbo Ramjet (GG-ATR) engine are conducted to investigate the feasibility of ethanol fuel, as comparing Liquefied Hydrogen (LH2), Liquefied Natural Gas ( LNG ), and $n-\mathrm{C}_{12} \mathrm{H}_{26}$. Liquefied Oxygen(LOX) is considered as an oxidizer. Gas generator combustion temperature and compressor pressure ratio are selected as the analytical parameters, which are varied from 900 to $1700 \mathrm{~K}$ and from 2.0 to 4.0 , respectively.

In general, specific impulses of light molecule weight fuels, such as LH2 and LNG are higher than those of large molecule weight fuel. For storable fuel, Isp of ethanol is larger than that of $n-\mathrm{C}_{12} \mathrm{H}_{26}$ when gas generator temperature is less than $1300 \mathrm{~K}$, although specific heat release of ethanol is only two thirds of $n-C_{12} H_{26}$ heat release. The main chemical species of n- $\mathrm{C}_{12} \mathrm{H}_{26}$ gas generator (GG) combustion gas are $\mathrm{CH}_{4}$ and $\mathrm{CO}$. On the other hand, ethanol GG combustion gas is mainly composed of $\mathrm{H}_{2}$ and $\mathrm{CO}$, resulting smaller molecular weight than $n-C_{12} H_{26}$. These characteristics contribute to larger Isp of ethanol than $n-C_{12} H_{26}$ and indicate the feasibility of ethanol to GG-ATR engine fuel.
\end{abstract}

Keywords

Air Turbo Ramjet Engine, Supersonic UAV, Gas Generator, Ethanol 


\section{NOMENCLAUTURE}

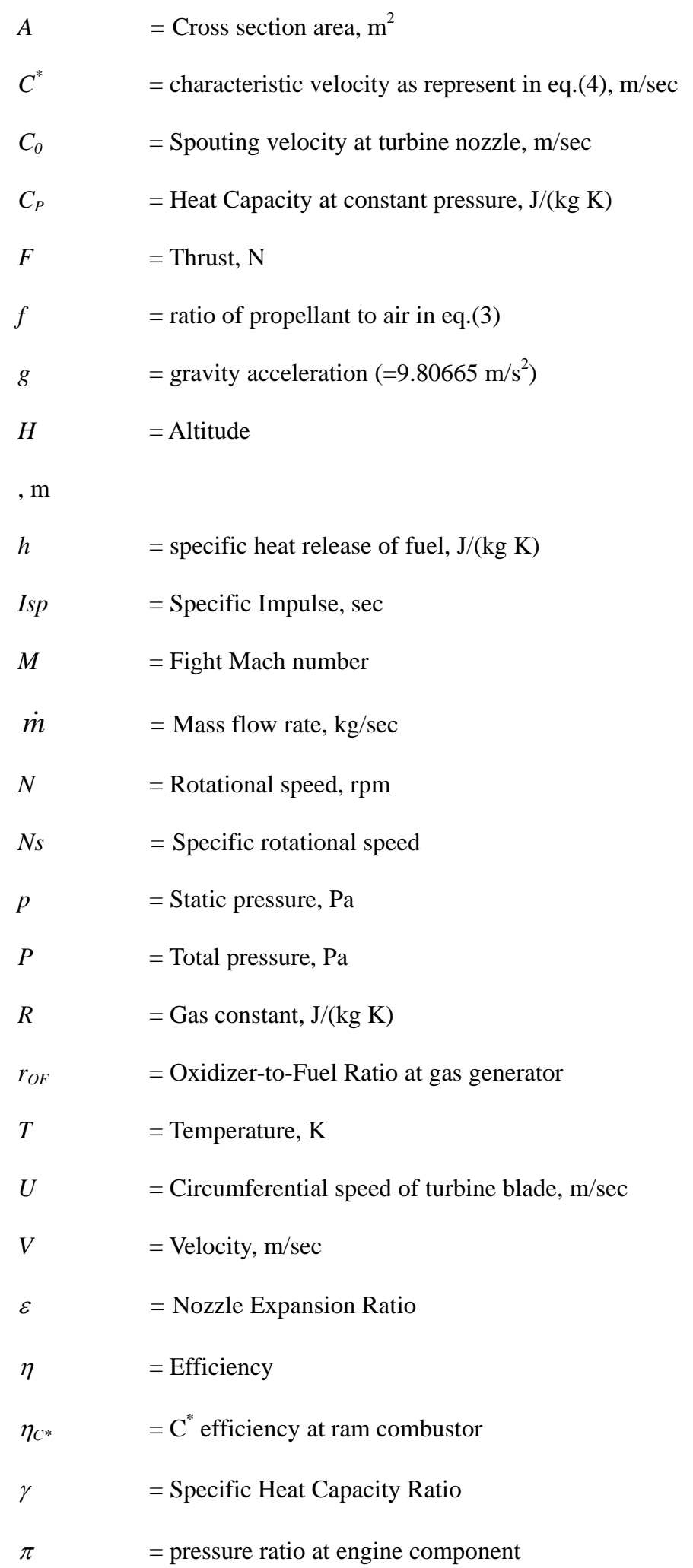

\section{Subscript}

air airflow

atm atmospheric condition 


$\begin{array}{ll}\text { comp } & \text { Compressor } \\ \text { cor } & \text { Corrected value } \\ \text { de } & \text { On-design condition } \\ \text { ext } & \text { exit condition } \\ \text { GG } & \text { Gas Generator } \\ \text { nozzle } & \text { nozzle } \\ \text { ram } & \text { Ram combustor } \\ \text { SLS } & \text { Sea level static condition } \\ \text { throat } & \text { Turbine nozzle throat } \\ \text { turb } & \text { turbine }\end{array}$

\section{Introduction}

An air turborocket (ATR) engine is expected as a propulsion engine for a future spaceplane or a hypersonic vehicle. There are two types of ATR engines, one is an expander cycle ATR (ATREX) engine (Ref.1) and the other one is gas-generator cycle ATR (GG-ATR) engine (Refs.2-7). The latter one is often called as Air Turborocket engine. However, it is called as GG-ATR engine in the present study. The studies of GG-ATR engine have been done by many researchers. Bussi et. al. conducted the analysis of on- and off-design performances for hydrogen fueled GG-ATR engine. They highlighted the turbomachinery characteristics of GG-ATR engine in their analysis (Ref.3). Christensen analyzed flight vehicle capabilities in conjunction with propulsion performances, comparing GG-ATR engine with a solid rocket motor (SRM) and a turbojet engine. ATR powered vehicle has nearly double the range of a SRM powered vehicle and the same range with two thirds flight time of a turbojet powered vehicle (Ref.4). Moreover, the subscale supersonic unmanned aerial vehicle (UAV) project is proceeding at Aerospace Plane Research Center(APReC), Muroran Institute Technology, Japan and GG-ATR engine is assumed for its propulsion engine (Ref.8). Figure 1 indicates the schematic of GG-ATR engine and Figure 2 shows the GG-ATR engine for the supersonic UAV, which is developed in Muroran Institute of Technology. Different from a conventional turbojet engine, compressor discharged air is not utilized to drive a turbine, but fuel riched gas-generator (GG) combustion gas is used. GG combustion gas mixes with air and burn at a ram combustor after driving the turbine. The ram combustor gas temperature is depended on the ratio of GG combustion gas to air flow rate and possibly exceeds temperature at a turbojet afterburner. Thus, greater thrust per frontal area can be expected than the turbojet engine with afterburner. In addition, a turbine inlet gas temperature or a GG combustion temperature is determined by oxidizer-to-fuel ratio at GG and not affected by flight speed, which means the GG-ATR engine can operate from sea-level static condition to high velocity condition ( up to Mach 4 ). Those 
characteristics give a very unique operation to GG-ATR engine. The drawbacks of GG-ATR engine is that not only fuel but also oxidizer must be onboard, resulting of lower specific impulse (Isp) than the conventional turbojet engine.

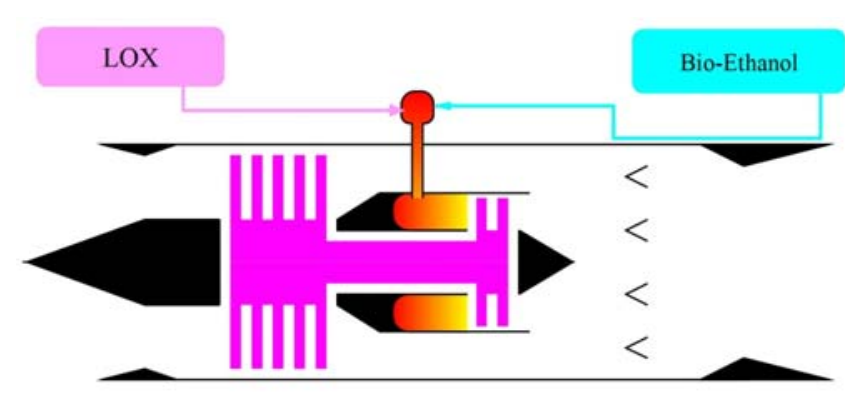

Figure 1 Schematic of GG-ATR engine

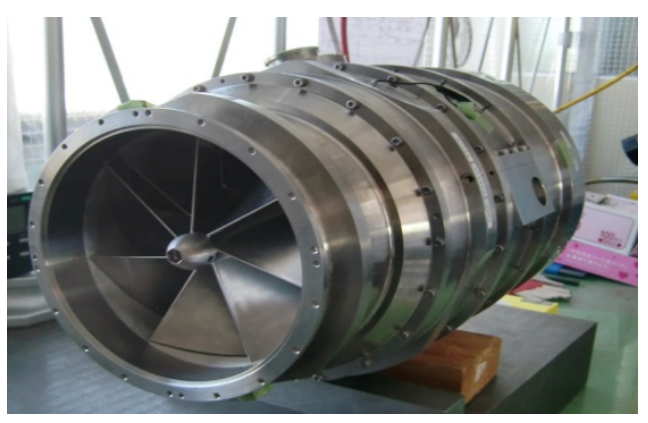

Figure 2 GG-ATR Engine developed in

Muroran Institute of Technology

Therefore, selection of a fuel and oxidizer is very crucial for GG-ATR engine performance. If the oxidizer is not employed, solid propellant or mono-propellant can be candidates for GG-ATR engine application (ref.4). The solid propellant ATR can be throttled by gas generator (GG) valve, which is located at upstream of turbine nozzle, and is difficult to shut down completely. Throttling of the solid propellant GG is associated with two-throats-in-series problem. The GG valve controls the gas flow rate and the GG pressure, which affects on the burning rate of solid propellant significantly. The throat of GG valve has mechanical moving parts and is always exposed on high temperature GG combustion gas during ATR engine operation, resulting of the difficulties of thermal design of the GG valve. On the other hand, typical monopropellants are hydrazine or monomethyl-hydrazine (MMH). Those monopropellants are thermally decomposed by catalyst, which are exothermic reactions. Turbine inlet temperature is determined by the rates of those thermal decomposition reactions, which are usually controlled by catalyst. Unfortunately, hydrazine and MMH are very toxic and have handling difficulties.

Because of aforementioned reasons, solid propellant and monopropellant are excluded from our GG-ATR engine application. Therefore, liquid bipropellant is considered as the favorable candidate for our engine. The previous studies mainly focused on liquefied hydrogen (LH2) fuel because LH2 has highest heat release and is the most promising fuel for an aerospace vehicle. However, LH2 has difficulties to handling and needs larger volume of a propellant tank because of its low density. Aviation kerosene and ethanol are high density, storable and easy handling. On the other hand, soot formation in the gas generator can be serious problem for kerosene fuel. Authors consider that ethanol would be utilized as fuel for GG-ATR engine, because ethanol is expected to have less soot formation than kerosene. However, ethanol has only two-thirds specific heat release of kerosene. The specific heat 
release of fuel is very important parameter for a turbojet engine because turbojet combustor gas is burnt under fuel-lean condition and mainly composed of air. High specific heat release of fuel can reduce fuel flowrate to obtain maximum allowable turbojet combustor gas temperature. That improves specific impulse, $I_{s p}$ or specific fuel consumption of turbojet engine. On the other hand for GG-ATR engine, high $C_{P}$ GG combustion gas is more favorable for GG-ATR engine, rather than high specific heat release of fuel, because the high $C_{P}$ GG combustion gas can produce larger turbine work and reduces its flowrate required to drive the turbine, resulting of higher $\mathrm{I}_{\mathrm{sp}}$. This characteristic is indicated that possibility of ethanol fuel for GG-ATR engine application. The purpose of the present study to evaluate ethanol fueled GG-ATR engine by parametric analyses with GG combustion temperature $T_{G G}$, and compressor pressure ratio, $\pi_{\text {comp }}$ and gains an insight into the feasibility of ethanol fuels for GG-ATR engine.

\section{Analytical Methods}

\subsection{GG-ATR engine performance and propellants}

Performance of air breathing engine is usually evaluated by specific thrust and specific impulse (Isp). The specific thrust means thrust produced by per unit mass airflow rate and Isp is thrust per unit mass flow rate of propellant. Specific thrust is very important parameter for engine designers to determine an engine size. Specific thrust and Isp are represented by the following equation (1) and (2), respectively.

$$
\begin{aligned}
& \frac{F}{\dot{m}_{\text {air }}}=(1+f) \eta_{C^{*}} \sqrt{2 C_{P, \text { ram }} T_{\text {ram }}\left(1-\left(\frac{p_{\text {nozzle }}}{P_{\text {nozzle }}}\right)^{\frac{\gamma_{\text {nozzle }}-1}{\gamma_{\text {nozle }}}}\right)}-V+\frac{\left(p_{\text {nozzle }}-p_{\text {atm }}\right) A_{\text {nozzle }}}{\dot{m}_{\text {air }}} \\
& I_{S P}=\left(1+\frac{1}{f}\right) \frac{\eta_{C^{*}}}{g} \sqrt{2 C_{P, \text { ram }} T_{\text {ram }}\left(1-\left(\frac{p_{\text {nozzle }}}{P_{\text {nozzle }}}\right)^{\frac{\gamma_{\text {nozzle }}-1}{\gamma_{\text {nozle }}}}\right)}-\frac{V}{f g}+\frac{\left(p_{\text {nozzle }}-p_{\text {atm }}\right) A_{\text {nozzle }}}{\dot{m}_{\text {air }} f g}
\end{aligned}
$$

where $f$ is the Propellant-to-Air Ratio (PAR).

$$
f=\frac{\dot{m}_{G G}}{\dot{m}_{\text {air }}}=\frac{C_{P, A i r} T_{T, A i r}\left(\pi_{\text {comp }}^{\frac{\gamma-1}{\gamma}}-1\right)}{\eta_{\text {comp }} \eta_{\text {turb }} C_{P, G G} T_{G G}\left(1-\pi_{\text {turb }}^{\frac{\gamma_{G G}-1}{\gamma_{G G}}}\right)}
$$

Propellant-to-Air Ratio of a GG-ATR engine is corresponded to Fuel-to-Air Ratio of a conventional turbojet engine. Different from the turbojet engine, not only mass flow rate of fuel, but also that of oxidizer must be included in consideration for GG-ATR performance analysis. To avoid confusion, the term of Propellant-to-Air Ratio is used in the present study, rather than Fuel-to-Air Ratio. PAR is derived from compressor-turbine power balance and plays very crucial role in Isp. The lower PAR is, the higher Isp can be obtained. In addition, PAR can 
be varied with types of fuel and oxidizer. Possible oxidizers for GG-ATR are liquefied oxygen (LOX), dinitrogen tetraoxide $\left(\mathrm{N}_{2} \mathrm{O}_{4}\right)$, hydrogen peroxide $\left(\mathrm{H}_{2} \mathrm{O}_{2}\right)$ and nitric acid $\left(\mathrm{HNO}_{3}\right)$. Among them, LOX is selected as the oxidizer in the present study because it is the most widely used one. For fuels, liquefied hydrogen (LH2), liquefied natural gas (LNG), ethanol and normal- dodecane $\left(n-\mathrm{C}_{12} \mathrm{H}_{26}\right)$ are the objects of investigation. LH2 is one of the most ideal fuels for the aerospace vehicles because its high specific heat release. On the other hands, the drawbacks of LH2 are its low density, difficulties of storage, cryogenic fluid. These disadvantages lead to larger propellant tank volume, high cost and handling difficulties.

LNG is also cryogenic fluid, but can be stored at higher temperature (110K) than LH2. In addition, LNG has larger density than LH2. The main constituent of LNG is $\mathrm{CH}_{4}$ and the other constituents of LNG are light hydrocarbon species such as ethane and propane. Chemical constituents of the natural gas are different from its production area. In the present study, the chemical constituents of LNG are considered to be 88 volumetric percent of $\mathrm{CH}_{4}, 9$ percent of $\mathrm{C}_{2} \mathrm{H}_{6}$ and 3 percent of $\mathrm{C}_{3} \mathrm{H}_{8}$. Those fractions are same as the natural gas produced in Hokkaido, Japan.

$\mathrm{n}-\mathrm{C}_{12} \mathrm{H}_{26}$ is liquid fuel at room temperature and has high density $\left(750-790 \mathrm{~kg} / \mathrm{m}^{3}\right)$. Different from cryogenic fuel, $n-\mathrm{C}_{12} \mathrm{H}_{26}$ is easy handling. $\mathrm{n}-\mathrm{C}_{12} \mathrm{H}_{26}$ is one of the main constituents of aviation kerosene, such as JP-8 or Jet A-1. For GG-ATR application, JP-4 fuels had been utilized with $\mathrm{H}_{2} \mathrm{O}_{2}$ oxidizer (Ref.5). $n-\mathrm{C}_{12} \mathrm{H}_{26}$ is surrogate fuel for aviation kerosene in the present study because its chemical elements and specific heat release are very similar to aviation kerosene.

Ethanol is considered as fuel for author's GG-ATR engine because it is storable, high density and less soot formation in gas generator. Ethanol has been hardly utilized for aerospace fuel except for some rocket fuel applications because of its two-thirds heat release of aviation kerosene. However, the ratio of hydrogen atoms to carbon atoms (H/C ratio) in the ethanol molecule is 3 whereas about 2 for aviation kerosene. This means GG combustion gases for ethanol contain more $\mathrm{H}_{2}$ than $n-\mathrm{C}_{12} \mathrm{H}_{26}$ because it is usually burned in fuel rich condition. Higher fraction of hydrogen in GG combustion gas reduces its molecular weight. This means that more available work can be extracted from turbine driving gas and improvement of Isp can be expected.

\subsection{Turbomachinery and Gas Generator characteristics for on-design condition}

As indicated in eq.(3), turbomachinery and GG operations determine PAR. The gas generator combustion temperature, $T_{G G}$, is selected from $900 \mathrm{~K}$ to $1700 \mathrm{~K}$ by an increment of $200 \mathrm{~K}$ in the present study. With the specified $P_{G G}$, an oxidizer to fuel ratio $(\mathrm{O} / \mathrm{F})$ is determined by chemical equilibrium calculation to reduce $T_{G G}$ to the specified value.

The computational code for GG-ATR engine performance is developed by the author, including chemical 
equilibrium calculation. The chemical equilibrium calculation of the present code is thoroughly validated by comparison with Chemical Equilibrium Application by Gordon and McBride (Ref.9). The chemical compositions, heat capacity, $C_{P, G G}$ and molecular weight, $M_{W, G G}$ of the GG combustion gas can be also obtained by this chemical equilibrium calculation. Figure 3 shows the O/F ratio at GG for $\pi_{\text {comp }}=2.5$. LH2 has the largest O/F ratio among 4 fuels and ranges from 0.914 to 1.865 while that of ethanol ranges from 0.133 to 0.780 .

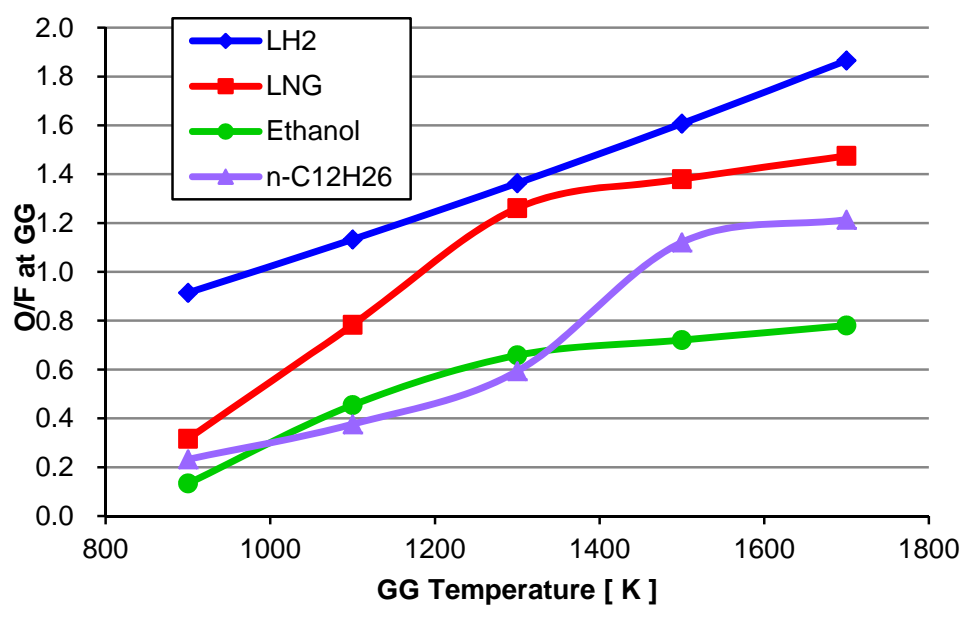

Figure 3 Oxidizer-to-Fuel ratios at GG for $\pi_{\text {comp }}=2.5$

Compressor pressure ratio, $\pi_{\text {comp }}$, is assumed as 2.0, 2.5, 3.0 and 4.0, while $\pi_{\text {comp }}$ of author's GG-ATR engine is equal to 2.5 in on-design point condition. Adiabatic efficiency of compressor $\eta_{\text {comp }}$, is fixed to 78.1 percent in the present analysis. This compressor efficiency is also equal to that of author's GG-ATR engine compressor, which is evaluated by CFD. Specific compression work can be simply determined by those conditions. Turbine expansion ratio, $\pi_{\text {turb }}$ is fixed to 5.0 in on-design point condition, which is also same as that of GG-ATR engine in Muroran Institute of Technology. If $\pi_{\text {comp }}$ becomes higher, $\pi_{\text {turb }}$ should be also higher because turbine exit pressure must be higher than the ram combustion pressure. Therefore, the GG pressure, $P_{G G}$ is linearly proportional to compressor pressure ratio, $\pi_{\text {comp }}$. Values of $P_{G G}$ and $\pi_{\text {comp }}$ are listed in Table.1 in the section 2.4. Higher $\pi_{\text {turb }}$ is preferable in view of engine performance, however, requires higher $P_{G G}$. Therefore, $\pi_{\text {turb }}$ of 5.0 is reasonable level.

Turbine efficiency is depended on the velocity ratio, $U / C_{0}$, where $U$ and $C_{0}$ are circumferential turbine blade velocity and spouting gas velocity from turbine nozzle, respectively (Ref.10). The turbine efficiencies in the present analysis use 0.9 times of the empirical data described in reference 10, which is indicated in Figure 4 . The turbine for the present GG-ATR engine is considered to be the impulse turbine, because molecular weight of turbine driving gas is smaller than air, resulting of greater $C_{0}$. This fact means that the turbine of the GG-ATR engine is similar to that of a rocket turbopump rather than a conventional turbojet engine. The spouting velocity 
$C_{0}$ is largely depended on the sonic speed of GG combustion gas and becomes greater for small molecular weight. The circumferential turbine blade velocity $U$ is fixed to $288.5 \mathrm{~m} / \mathrm{sec}$ and spouting Mach number at turbine nozzle is 1.2. Those values are also same as the GG-ATR engine in Muroran Institute of Technology. In the case of $T_{G G}=$ 1100K, typical turbine efficiencies at the design condition for LH2 are calculated as about 46 percent and about 70 percent for other 3 fuels. The turbine efficiency of the author's GG-ATR engine by CFD analysis is also indicated in Fig.4. CFD analysis of turbine flow is conducted by the commercial CFD software FINE ${ }^{\mathrm{TM}}$ / Turbo and Spalart Allmaras turbulence model is employed. In the on-design point condition of this GG-ATR engine, the rotational speed of turbine is $58000 \mathrm{rpm}$. The turbine inlet temperature and pressure are $1100 \mathrm{~K}$ and $1.35 \mathrm{MPa}$, respectively. For CFD analysis in Fig.4, the specific rotational speed of the turbine blade is ranged from 40 to 105 percent of the on-design point condition speed. The turbine inlet pressure is ranged from $0.60 \mathrm{MPa}$ to $1.35 \mathrm{MPa}$, where is assumed to be the actual operational range of the author's GG-ATR engine. CFD results in Fig.4 indicate that turbine efficiency is almost solely depended on the velocity ratio, $\mathrm{U} / \mathrm{C}_{0}$ and agree with the empirical turbine efficiency curve.

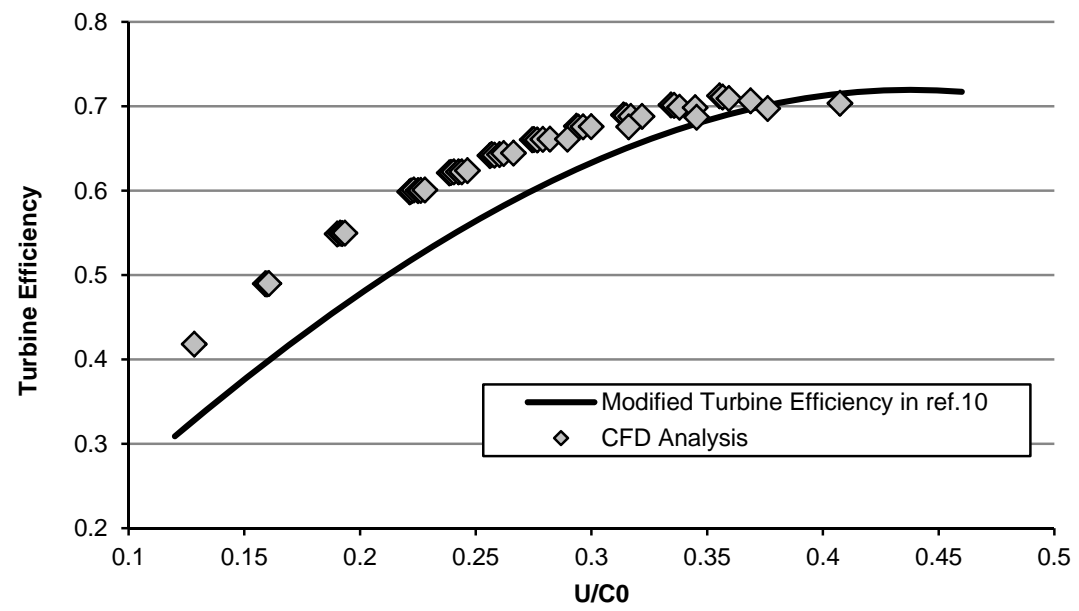

Figure 4 Turbine Efficiency Curve for the Present GG-ATR Engine Analysis

Christensen describes that turbine expansion flow should be treated as chemical equilibrium condition, while chemical frozen condition is identical to chemical equilibrium (Ref.6). In the present study, turbine expansion is considered as chemical frozen flow because of simplicity. Sullerey et. al. also adopted chemical frozen flow treatment and can obtain reasonable results (Ref.7).

\subsection{Off-Design Condition for Turbomachinery and Gas Generator}

Off design performance analysis is also treated in the present paper, and those analysis conditions are based on the on-design conditions as described in the previous section. For the analytical conditions of compressor, 
corrected air flow rate is linearly proportional to corrected rotational speed of turbomachinery, $N_{\text {cor }}$, and specific compressor work is proportional to the square of the rotational speed. Thus, this leads the following relation between $N_{\text {cor }}$ and $\pi_{\text {comp. }}$ (ref.11)

$$
N_{\text {cor }}^{2} \propto\left(\pi_{\text {comp }}\right)^{\frac{\kappa-1}{\kappa}}-1
$$

The turbine nozzle flow is considered to be choked at turbine nozzle. Therefore, the following relation can be established between mass flow rate of GG combustion gas, $m_{G G}$, and the gas generator pressure, $P_{G G}$.

$$
\begin{aligned}
& \frac{\dot{m}_{G G} C_{G G}^{*}}{P_{G G}}=\left(\frac{\dot{m}_{G G} C_{G G}^{*}}{P_{G G}}\right)_{d e}=A_{\text {throat }} \\
& C_{G G}^{*}=\sqrt{\frac{R T_{G G}}{\kappa_{G G}}\left(\frac{\kappa_{G G}+1}{2}\right)^{\frac{\kappa_{G G}+1}{\kappa_{G G}-1}}}
\end{aligned}
$$

where $A_{\text {throat }}$ and $C_{G G}^{*}$ are turbine nozzle throat area and characteristic velocity at the turbine nozzle, respectively. $A_{\text {throat }}$ is constant in both of on- and off- design conditions. As well as on-design condition, compressor work must be equal to the turbine work in off-design condition.

Based on equation (4) to (6), off-Design analysis procedures are done as follow.

1. Flight Mach number, altitude and actual rotational speed, $N$, are specified at first. $N_{C}$ can be reduced. The compressor inlet conditions are calculated by air intake performance analysis, which is described in the next section.

2. $\pi_{\text {comp }}$ and corrected air flow rate, $m_{\text {cor }}$, are determined by $N_{C}$ and the compressor work can be determined.

3. The velocity ratio $U / C_{0}$ is given from $N$. The turbine efficiency, $\eta_{t u r b}$, is given from Fig.4. Turbine expansion ratio, $\pi_{\text {turb }}$, is assumed to be 5 . GG combustion gas flow rate, $m_{G G}$, and GG combustion pressure, $P_{G G}$, are determined by iterative procedure to satisfy compressor-turbine power balance and equation (6). The initial values of $P_{G G}$ for iterative procedure are given by Table.1, which are also same as the maximum values of $P_{G G}$.

4. During this iterative procedure, $P_{G G}$ must be less than its maximum value. If not, actual rotational speed, $N$, is reduced. Moreover, the turbine exit pressure, $P_{\text {turb,ext }}$, must be more than the ram combustor pressure, $P_{\text {ram }}$. If not, $\pi_{\text {turb }}$ is reduced to be $P_{G G} / P_{\text {ram }}$.

5. Calculation is completed if the absolute relative approximate error of $P_{G G}$ is less than $10^{-5}$.

Figure 5 show the $C_{G G}^{*}$ at the gas generator of those 4 fuels for $\pi_{\text {comp }}=2.5$ as functions of $T_{G G}$. The conditions in Fig.5 are sea level static condition and the actual rotational speed, $N$, is on-design condition speed. $C_{G G}^{*}$ of LH2 exceeds $2000 \mathrm{~m} / \mathrm{sec}$ and has the highest among them because of its light molecular weight. $C_{G G}^{*}$ of the other 3 
fuels are ranged from 860 to $1500 \mathrm{~m} / \mathrm{sec}$

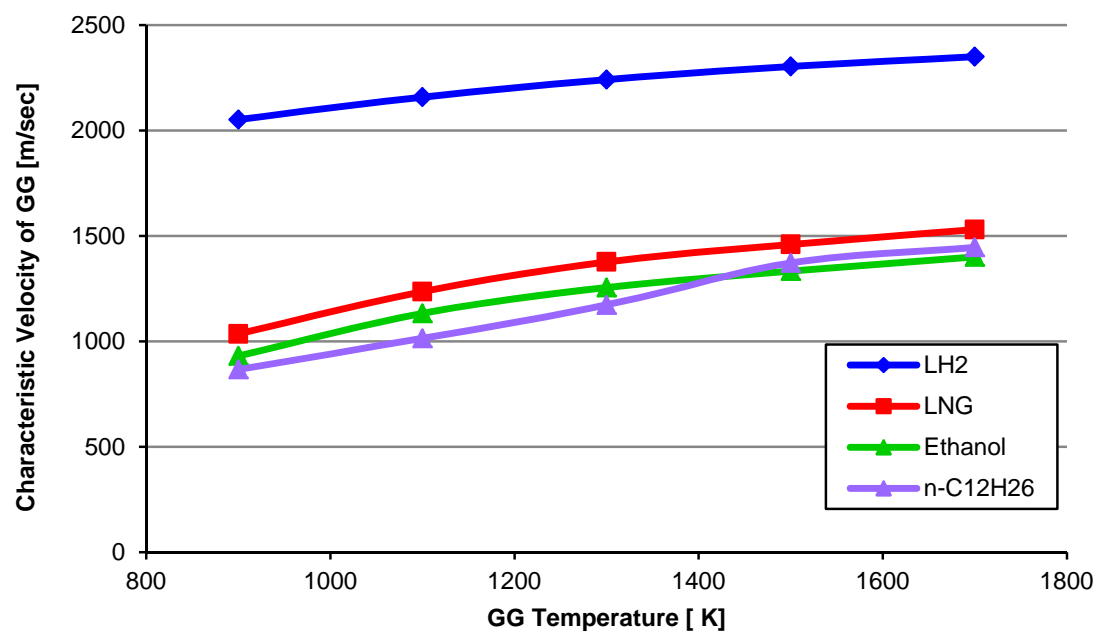

Figure 5 Characteristic Velocity at Gas Generator for $\pi_{\text {comp }}=2.5$

\subsection{Stationary components of GG-ATR engine analysis}

Stationary component performances such as an intake duct, a ram combustor and a nozzle must be included in engine performance evaluation. The total temperature, $T_{T, a t m}$ and pressure, $P_{T, a t m}$, of the incoming air are given by static temperature, pressure and flight Mach number. The ram recovery of the air intake, $\pi_{\text {intake }}$, and the duct pressure recovery, $\pi_{d u c t}$, must be taken into account for total pressure at the compressor inlet. The ram recovery of the intake is expressed by MIL-E-5008B and the total pressure recovery at the duct, $\pi_{\text {duct }}$, is given as 0.96 and constant for on- and off-design condition analysis.

No heat losses are assumed from the ram combustor, the nozzle and the intake duct. Ram combustor temperature, $T_{r a m}$, is evaluated by chemical equilibrium calculation under constant enthalpy-pressure condition. The pressure in the ram combustor, $P_{\text {ram }}$ is given as the compressor exit pressure with 3 percent of total pressure loss. The initial enthalpies for the ram combustion are defined on the basis of the compressor exit temperature for air, and the turbine exit temperature for GG combustion gas. The third term in eq.(1) and (2) are the contributions due to the pressure difference. The pressure difference on the nozzle exit plane is depended on $P_{\text {ram }}$, the atmospheric pressure $p_{a t m}$, and the nozzle expansion ratio, $\varepsilon$. In the present analysis, $\varepsilon$ is varied with $\pi_{\text {comp }}$ as listed in Table.1 to eliminate the effect of pressure differences due to $\pi_{\text {comp. }}$. Under conditions of $\varepsilon$ listed in table.1, the static pressure at the nozzle exit is approximately $40 \mathrm{kPa}$ abs. in the sea-level static condition. This static pressure level is nearly equal to the limit to confine flow separation in the nozzle at the ground level. For those nozzle expansion ratios in table.1, the ram combustor gas can exhaust from the nozzle with optimum expansion at Mach 1.3 and $11 \mathrm{~km}$ altitude. This flight condition is the typical transonic one. Therefore, nozzle expansion ratios listed 
in Table. 1 are reasonable in the view of practical application.

Table. 1 Nozzle expansion ratio $\varepsilon$ and $P_{G G}$ with $\pi_{\text {comp }}$.

\begin{tabular}{|c|c|c|}
\hline$\pi_{\text {comp }}$ & $\varepsilon$ & $\begin{array}{l}P_{G G} \\
{[\mathrm{MPa}]}\end{array}$ \\
\hline 2.0 & 1.40 & 10.8 \\
\hline 2.5 & 1.60 & 13.5 \\
\hline 3.0 & 1.75 & 16.2 \\
\hline 4.0 & 2.10 & 21.6 \\
\hline
\end{tabular}

Nozzle expansion flow is treated as chemical frozen flow for simplicity, which underestimates specific thrust and Isp. However, $\mathrm{C}^{*}$ efficiency, $\eta_{c^{*}}$ at the throat of the ram combustor is assumed as 100 percent. Theoretical $C^{*}$ is defined as equation (8).

$$
C^{*}=\sqrt{\frac{R T_{\text {ram }}}{\kappa_{\text {ram }}}\left(\frac{\kappa_{\text {ram }}+1}{2}\right)^{\frac{\kappa_{\text {ram }}+1}{\kappa_{\text {ram }}-1}}}
$$

where $\kappa_{\text {ram }}$ is the specific heat capacity ratio of the ram combustor gas. $\mathrm{C}^{*}$ efficiency, $\eta_{\mathrm{C}^{*}}$ is defined as the ratio of the actual characteristic velocity to theoretical ones. This assumption overestimates specific thrust and Isp. Those two assumptions are balanced each others.

\subsection{Code Validation with Experimental Data of Air Turbo Ramjet Engine}

The analytical code developed by the author is validated by comparison with the experimental data of Air Turbo Ramjet engine, which is obtained by Lilley et. al. (Ref.12). Hydrazine fueled monopropellant gas generator is equipped in their ATR engine, which utilized the catalyst to decompose hydrazine exothermically. In their test program, five different engine configurations were tested and the original engine configuration is designated as Build 1. The latest configuration in their program was designated as Build 5, which employs the improved ram combustor mixer. The analytical code is compared with the experimental result of Build 5 configuration in ref.12. The rotational speed of their ATR engine is $68000 \mathrm{rpm}$ in on-design condition. The analytical results by the present code and the experimental data in ref.12 are compared in the range from 40000 to 68000 rpm, where specific rotational speed, $N_{S}$, is corresponded from 0.588 to 1.0 .

The catalytic decomposition of hydrazine $\left(\mathrm{N}_{2} \mathrm{H}_{4}\right)$ is done by two part reactions. The first part is exothermic reaction which all of $\mathrm{N}_{2} \mathrm{H}_{4}$ decomposes into $\mathrm{N}_{2}$ and $\mathrm{NH}_{3}$. Some of $\mathrm{NH}_{3}$ is converted into $\mathrm{N}_{2}$ and $\mathrm{H}_{2}$ by the endothermic secondary reaction. Conversion ratio of $\mathrm{NH}_{3}$ into $\mathrm{N}_{2}$ and $\mathrm{H}_{2}$ determines turbine inlet temperature. Turbine inlet temperature is also given in ref.12. The catalytic decomposition process of $\mathrm{N}_{2} \mathrm{H}_{4}$ cannot be calculated by chemical equilibrium analysis, which is based on the Gibbs free energy minimization. 


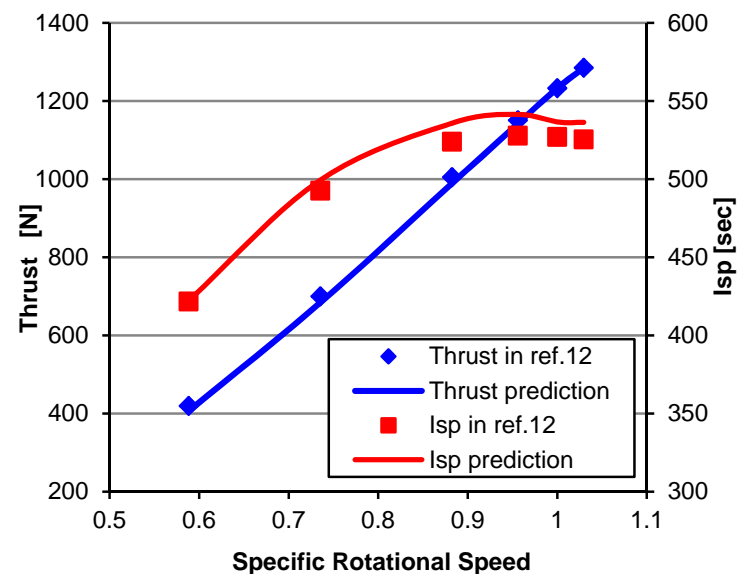

Figure 6 Analytical and Experimental Thrust and Isp of Hydrazine Fueled GG-ATR engine

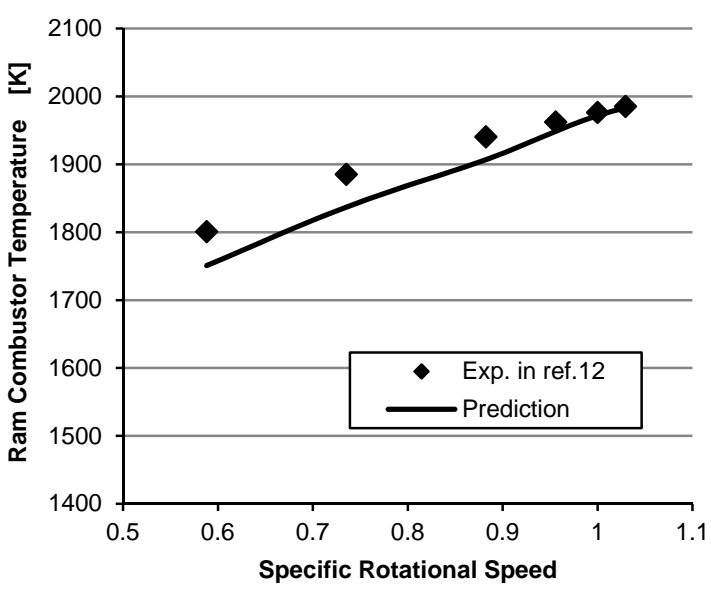

Figure 7 Analytical and Experimental Ram Combustor Temperature of Hydrazine Fueled GG-ATR engine

Figure 6 indicates thrust and Isp of hydrazine fueled ATR engine and compares the experimental and analytical results. The engine operation conditions, such as compressor pressure ratio, $\pi_{\text {comp }}$, compressor efficiency, $\eta_{\text {comp }}$, turbine expansion ratio, $\pi_{\text {turb }}$, turbine efficiency, $\eta_{\text {turb }}$, and turbine inlet temperature are described in ref.12 and those data are utilized in the present analysis. In ref.12, combustion efficiency at the ram combustor, $\eta_{\text {ram }}$ is defined as the ratio of the experimental to theoretical temperature rise at the ram combustor. The present code validation also considers the combustion efficiency at the ram combustor. Unfortunately, ram combustor pressure ratio, $\pi_{\text {ram }}$, is not described in ref.12. If $\pi_{\text {ram }}$ is assumed to be 0.88 , which means the ram combustor pressure loss is assumed to be 12 percent of total pressure, the analytical predictions of thrust and Isp by the present code indicate good agreement with the experimental data as shown in Fig.6. Figure 7 indicates the analytical prediction and experimental data of the ram combustor temperature, $T_{\text {ram }}$.

For both of Isp and $T_{\text {ram }}$, the maximum errors between the analytical prediction and experimental data are less than 2.7 percent. The maximum error of thrust prediction is about 3.1 percent. Although thrust and Isp can be affected by $\pi_{\text {ram }}$, $T_{\text {ram }}$ is nearly independent to $\pi_{\text {ram }}$ and analytical $T_{\text {ram }}$ agree well to the experimental ones. Therefore, the comparisons of analytical prediction to the experimental data in Fig.5 and Fig.6 show good accuracy of the present analytical code.

\section{Analytical Result and Discussion}

\subsection{Specific Thrust and Ram Combustor Temperature}

The influences of $T_{G G}$ and $P_{G G}$ on specific thrust and ram combustor temperature, $T_{\text {ram }}$, are investigated in this section. Although the extreme high $T_{G G}$ condition is unrealistic because of excessive heat load on a turbine blade, 
it is necessary to investigate in higher $T_{G G}$ conditions to explore the thermodynamic mechanism of GG-ATR engine cycle.

Figure 8 indicates the specific thrusts for $\pi_{\text {comp }}=2.5$ and 4.0 as functions of $T_{G G}$. As shown in Fig.8, LNG, Ethanol and $n-\mathrm{C}_{12} \mathrm{H}_{26}$ have the maximum specific thrust concerned with $T_{G G}$ while specific thrust of LH2 is monotonically decreased as $T_{G G}$ increases. For $\pi_{\text {comp }}=2.5$, the maximum specific thrusts of LNG and ethanol exist at $T_{G G}=1100 \mathrm{~K}$ and that of $\mathrm{n}-\mathrm{C}_{12} \mathrm{H}_{26}$ does at $T_{G G}=1300 \mathrm{~K}$. For $\pi_{\text {comp }}=4.0$, the maximum specific thrusts for those 3 fuels shift to higher $T_{G G}$ than those for $\pi_{\text {comp }}=2.5$. Specific thrust of LH2 is the largest among those 4 fuels except for some conditions. Specific thrusts of $n-C_{12} H_{26}$ and ethanol are contrastive with each other. For ethanol, the maximum specific thrust is located at $T_{G G}=1100 \mathrm{~K}$ while it is at $T_{G G}=1300 \mathrm{~K}$ or $1500 \mathrm{~K}$ for $n-\mathrm{C}_{12} \mathrm{H}_{26}$. Specific thrust of ethanol is superior to $n-\mathrm{C}_{12} \mathrm{H}_{26}$, when $T_{G G}$ is less than around $1300 \mathrm{~K}$, however, it turns to be smaller than n- $\mathrm{C}_{12} \mathrm{H}_{26}$ if $T_{G G}$ exceeds this temperature. Specific thrusts of LNG have intermediate characteristics between ethanol and $n-\mathrm{C}_{12} \mathrm{H}_{26}$. Considering practical application of GG-ATR engine, lower $T_{G G}$ is preferable because thermal limit of turbine blade material. Moreover, it is very difficult to provide film or transpiration cooling system to the turbine of GG-ATR engine because coolant for those cooling system is usually air and GG combustion gas is fuel-rich one. The limitation of $T_{G G}$ may be less than $1100 \mathrm{~K}$ without turbine cooling.

Figure 9 show the effect of $\pi_{\text {comp }}$ on specific thrust. The larger $\pi_{\text {comp }}$ is, the greater specific thrust can be obtained. For $T_{G G}=1100 \mathrm{~K}$, the differences of the specific thrusts among those 4 fuels become greater as $\pi_{\text {comp }}$ is increased. The specific thrust of $n-\mathrm{C}_{12} \mathrm{H}_{26}$ is the smallest among them when $\pi_{\text {comp }}$ is more than 2.5. For $T_{G G}=$ $1700 \mathrm{~K}$, the specific thrusts for those 4 fuels extend in parallel as $\pi_{\text {comp }}$ is increased. Ethanol has the smallest specific thrust among 4 fuels.

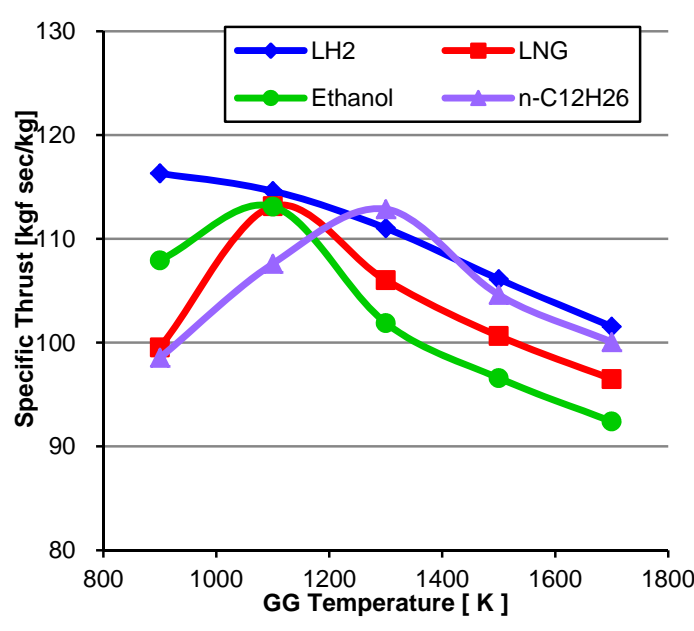

(a) $\pi_{\text {comp }}=2.5$

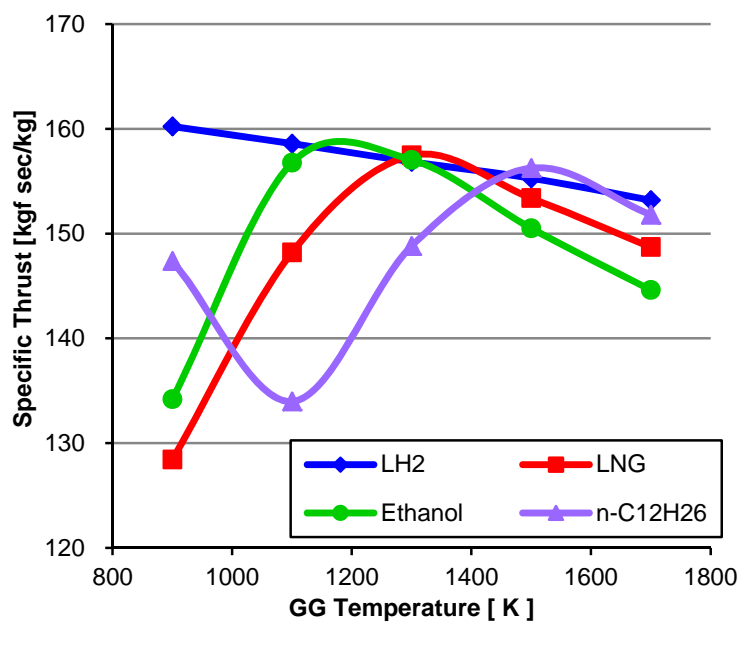

(b) $\pi_{\text {comp }}=4.0$

Figure 8 Specific thrusts as functions of $T_{G G}$ for $\pi_{\text {comp }}=2.5$ and 4.0 


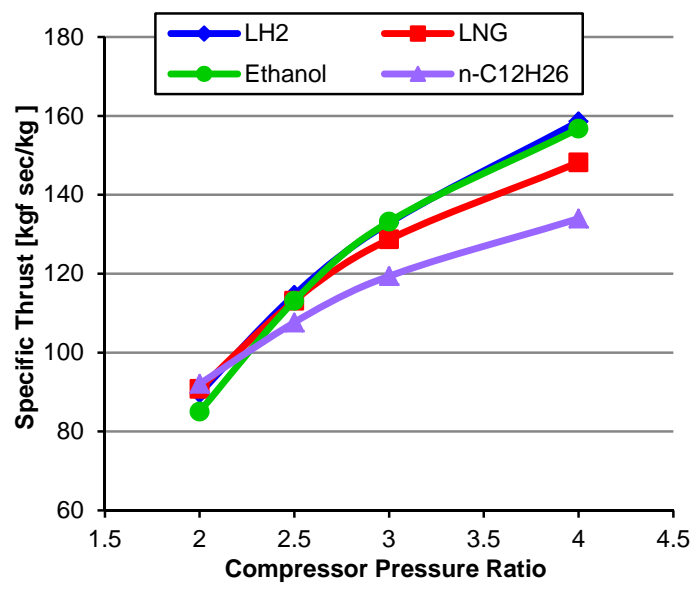

(a) $T_{G G}=1100 \mathrm{~K}$

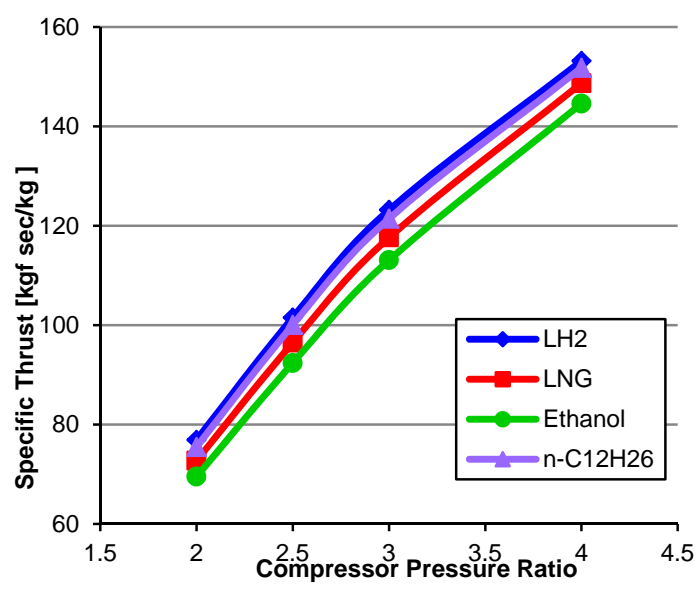

(b) $T_{G G}=1700 \mathrm{~K}$

Figure 9 Specific thrusts as functions of $\pi_{\text {comp }}$ for $T_{G G}=1100 \mathrm{~K}$ and $1700 \mathrm{~K}$

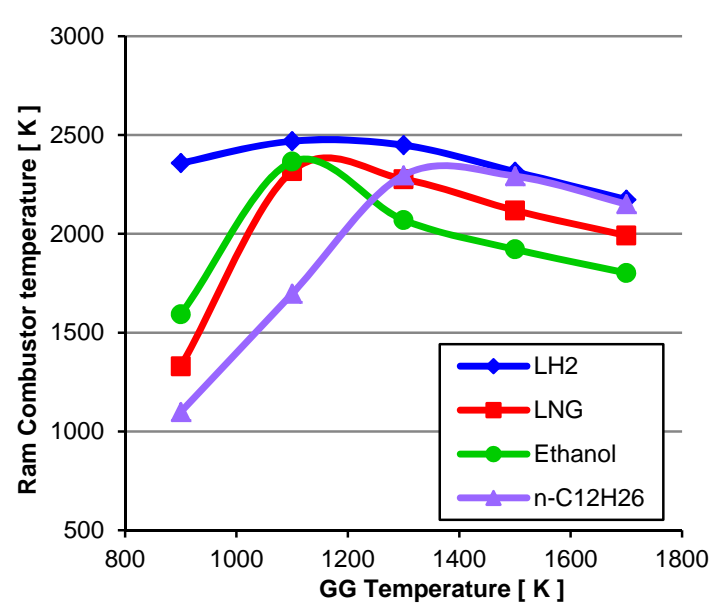

(a) $\pi_{\text {comp }}=2.5$

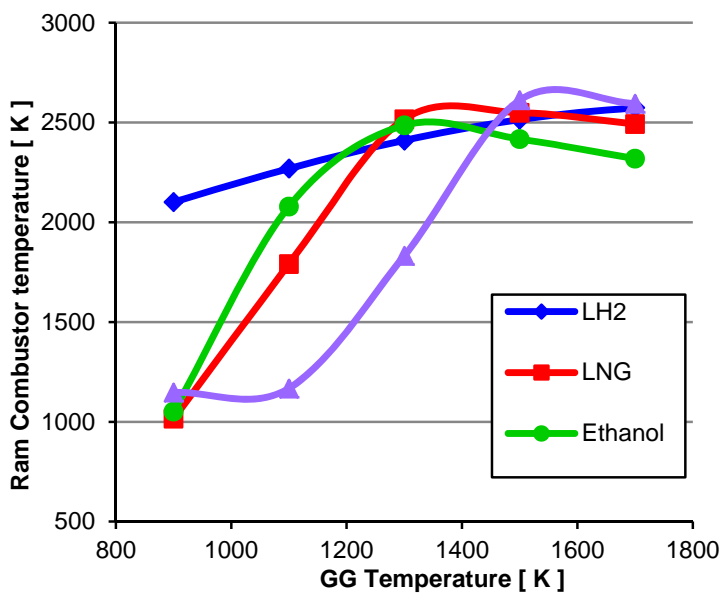

(b) $\pi_{\text {comp }}=4.0$

Figure 10 Ram Combustor Temperature $T_{\text {ram }}$ as functions of $T_{G G}$ for $\pi_{\text {comp }}=2.5$ and 4.0

Figure 10 shows the ram combustor temperature, $T_{\text {ram }}$, as functions of $T_{G G}$ for 4 fuels. $\pi_{\text {comp }}$ are equal to 2.5 and 4.0. $T_{\text {ram }}$ of those 4 fuels have the maximum values with $T_{G G}$. The mixing of GG combustion gas with the air is largely affected on the combustion efficiency and the ram combustor temperature, $T_{\text {ram }}$. Low mixing efficiency can decrease them, resulting of lower thrust and Isp. Mixing processes at the ram combustor are similar to that at an afterburner of turbojet engine. In the previous studies of combustion efficiencies at the ram combustor or the afterburner, reference 13 discusses about the combustion efficiency at the afterburner of TF30-P-3 turbofan engine, which is ranged from 68 to 91 percent. In Lilley’s ATR engine test in ref.12, combustion efficiency at the ram combustor is about 80 percent. Therefore, those experimental studies imply that the combustion efficiency more than 90 percent requires very sophisticatedly designed mixer in the ram combustor. However, the present analysis focuses on the propellant characteristics and considers that mixing processes are depended on fluid dynamic 
characteristics in the ram combustor, rather than chemical properties of propellants. Thus, it is assumed that mixing of GG combustion gas mix with the air is ideally completed. The maximum $T_{\text {ram }}$ in Fig.10 indicates that stoichiometric combustion occurs at the ram combustor. Stoichiometric combustion in the ram combustor is depended on PAR in eq.(3), or the ratio of the combustible gas in GG combustion gas and the air. Both of $T_{G G}$ and $\pi_{\text {comp }}$ largely influence on PAR, which determines whether the ram combustion is fuel-rich or fuel lean conditions. Higher $\pi_{\text {comp }}$ increase compression work, which requires higher $T_{G G}$ or larger GG combustion gas flow rate. GG combustion gas is always burned in fuel-rich condition; therefore, the amounts of combustible gas species are decreased in the GG combustion gas if $T_{G G}$ become higher. For those 4 fuels, $T_{G G}$ with the maximum $T_{\text {ram }}$, move from lower side to higher side as $\pi_{\text {comp }}$ increase.

The ram combustor gas is burned under fuel rich condition for lower $T_{G G}$ than the maximum $T_{\text {ram }}$ condition. On the other hand, fuel lean combustion is done for higher $T_{G G}$ than the maximum $T_{\text {ram }}$. In the case of $\pi_{\text {comp }}=2.5$, the maximum $T_{\text {ram }}$ is located at $T_{G G}=1100 \mathrm{~K}$ for $\mathrm{LH} 2$, LNG and ethanol and $T_{G G}=1300 \mathrm{~K}$ for n- $\mathrm{C}_{12} \mathrm{H}_{26}$. As mentioned previously, applicable $T_{G G}$ should be less than $1100 \mathrm{~K}$. If gas generator would be operated in the condition of $T_{G G}=1100 \mathrm{~K}$, the ram combustion is done under nearly stoichiometric condition for LH2, LNG and ethanol and high $T_{\text {ram }}$ can be achieved. However, for $n-\mathrm{C}_{12} \mathrm{H}_{26}$, the ram combustion is done under fuel rich condition, thus $T_{\text {ram }}$ is significantly less than other 3 fuels. Low $T_{\text {ram }}$ deteriorates specific thrust and Isp. This means that $n-\mathrm{C}_{12} \mathrm{H}_{26}$ fueled ram combustion gas contains unburned combustible gas and exhaust from the nozzle, which does not contribute to thrust production. If those combustible gases are burned and utilized to produce thrust, additional oxidizer needs to be injected into the ram combustor.

As comparing Fig.8 with Fig.10, higher $T_{\text {ram }}$ roughly leads to larger specific thrust. However, $T_{\text {ram }}$ is not always proportional to specific thrust. For example, in the case of $\pi_{\text {comp }}=4.0$, the specific thrust of LH2 is monotonously decreased as $T_{G G}$ is increased while $T_{\text {ram }}$ is monotonously increased. The key factors to determine the specific thrust are $T_{\text {ram }}$, PAR and the heat capacity at constant pressure in ram combustor, $C_{P, r a m}$. If $T_{G G}$ is lower, PAR is increased as indicated in eq.(3). Larger PAR causes fuel rich combustion in the ram combustor and increases $C_{P \text {,ram }}$ because light molecular weight species are much contained in the ram combustor gas. Even if $T_{\text {ram }}$ is reduced by larger PAR, the term of $C_{P, r a m} T_{\text {ram }}$ is nearly constant and ranged from $4.80 \mathrm{MJ} / \mathrm{kg}$ to $4.94 \mathrm{MJ} / \mathrm{kg}$, where $T_{G G}$ is from $900 \mathrm{~K}$ to $1700 \mathrm{~K}$. In addition, larger PAR at lower $T_{G G}$ can contribute to increase the specific thrust as indicated in eq.(1). That is why specific thrust and $T_{\text {ram }}$ of LH2 show the contrary behaviors in Fig.8 and Fig.10. Another remarkable disagreement of specific thrust and $T_{\text {ram }}$ is those of $\mathrm{n}-\mathrm{C}_{12} \mathrm{H}_{26}$ for $\pi_{\text {comp }}=4.0$ and $T_{G G}=900 \mathrm{~K}$. The specific thrust of $\mathrm{n}-\mathrm{C}_{12} \mathrm{H}_{26}$ in this condition is apparently greater than that at $T_{G G}=1100 \mathrm{~K}$, however, $T_{\text {ram }}$ at $T_{G G}=1100 \mathrm{~K}$ is nearly equal to $T_{\text {ram }}$ at $T_{G G}=900 \mathrm{~K}$. As well as the above mentioned case, PAR become larger at $T_{G G}=900 \mathrm{~K}$. In addition, if PAR is too large, the ram combustion is inclined to fuel-rich condition, 
resulting of reduced $T_{\text {ram }}$. The mass flow rate of the GG combustion gas is increased and contributes to increase specific thrust. Those results indicate that the specific thrust of GG-ATR engine involves $T_{\text {ram }}$, PAR and $C_{P \text {,ram }}$ complicatedly.

\subsection{Analyses of Isp and GG combustion gas for GG-ATR engine}

Specific impulse, Isp, is one of the most important parameter to evaluate aerospace propulsion performance. GG-ATR engine also has a tradeoff between specific thrust and Isp as well as other aerospace propulsion engines. From the viewpoint of engine design, Isp should be at the maximum while meeting various design constraints, such as the engine size, thrust level and life time.

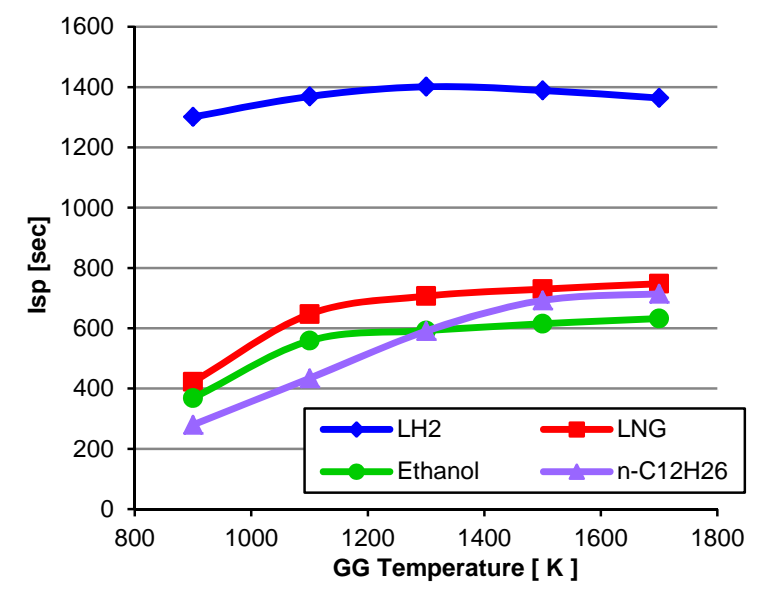

(a) $\pi_{\text {comp }}=2.5$

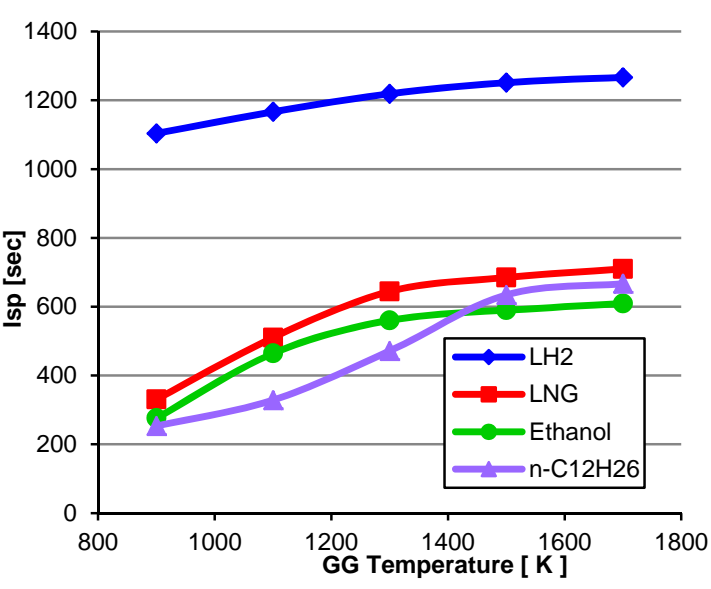

(b) $\pi_{\text {comp }}=4.0$

Figure 11 Specific Impulse of GG-ATR engine as function of $T_{G G}$ for $\pi_{\text {comp }}=2.5$ and 4.0

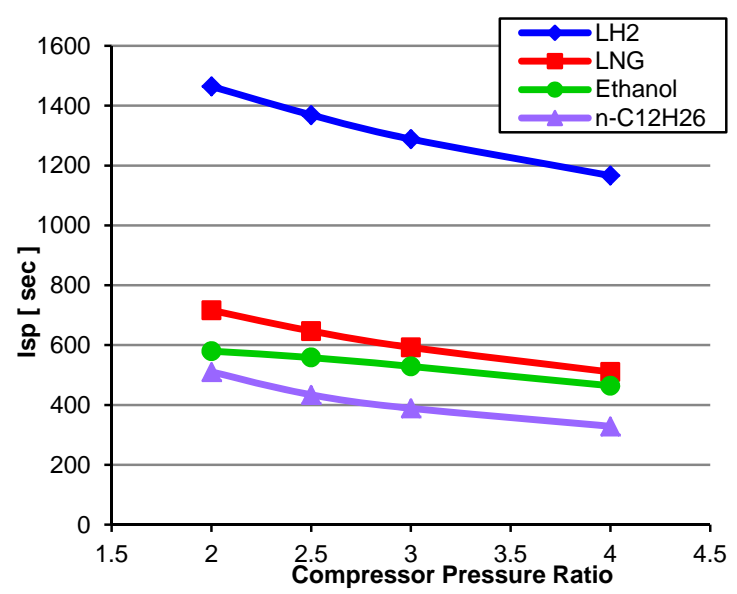

(a) $T_{G G}=1100 \mathrm{~K}$

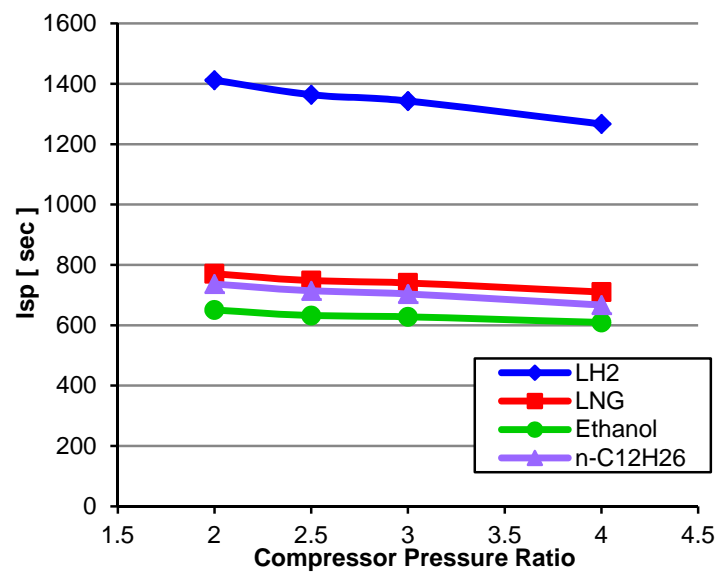

(b) $T_{G G}=1700 \mathrm{~K}$

Figure 12 Specific Impulse of GG-ATR engine as function of $\pi_{\text {comp }}$ for $T_{G G}=1100 \mathrm{~K}$ and $1700 \mathrm{~K}$

Figure.11 shows Isp of GG-ATR engine as functions of $T_{G G}$, for $\pi_{\text {comp }}=2.5$ and 4.0 and Figure 12 indicates 
those as functions of $\pi_{\text {comp }}$ for $T_{G G}=1100 \mathrm{~K}$ and $1700 \mathrm{~K}$. In Fig.11, Isp for LNG, ethanol and n- $\mathrm{C}_{12} \mathrm{H}_{26}$ are monotonically increased as $T_{G G}$ increases. On the other hands, Isp of LH2 has the maximum value where $T_{G G}$ is $1300 \mathrm{~K}$ for $\pi_{\text {comp }}=2.5$. In Fig.12, Isp is inversely proportional to compressor pressure ratio, $\pi_{\text {comp }}$. Isp at $T_{G G}=1100 \mathrm{~K}$ is more rapidly decreased than at $T_{G G}=1700 \mathrm{~K}$, as $\pi_{\text {comp }}$ increases.

LH2 has the highest Isp among those fuels and LNG has the second highest one. For storable fuel, Isp of Ethanol is higher than $n-\mathrm{C}_{12} \mathrm{H}_{26}$ when $T_{G G}$ is less than $1300 \mathrm{~K}$. This tendency is also appeared in Fig.12. Isp of ethanol is greater than $\mathrm{n}-\mathrm{C}_{12} \mathrm{H}_{26}$ for $T_{G G}=1100 \mathrm{~K}$ in any $\pi_{\text {comp }}$ conditions. On the other hand, for $T_{G G}=1700 \mathrm{~K}$, ethanol has lower Isp than $\mathrm{n}-\mathrm{C}_{12} \mathrm{H}_{26}$ for $T_{G G}=1700 \mathrm{~K}$. The magnitude order of Isp mainly depends on $T_{G G}$ rather than $\pi_{\text {comp. }} T_{G G}$ should be less than $1100 \mathrm{~K}$ because of thermal limitation of turbine blade. It is very surprising that ethanol is superior to $n-\mathrm{C}_{12} \mathrm{H}_{26}$ for practical application of GG-ATR engine, although ethanol has only two-thirds specific heat release of $n-\mathrm{C}_{12} \mathrm{H}_{26}$. Specific heat release of fuel is crucial to Isp of rocket and aero- engine. Actually, Isp is proportional to specific heat release for a conventional turbojet or a turbo fan engine (ref.14). That is one of the reasons that ethanol has been hardly used for aero-engine fuel. However, the results in Fig.11 and 12 indicate that GG-ATR engine is not subject to this proportional relation and ethanol is promising fuel for GG-ATR engine. This characteristic of GG-ATR engine is quite different from a conventional turbojet engine. To investigate the mechanism of Isp of those 4 fuels, propellant-to-air ratio, PAR for $\pi_{\text {comp }}=2.5$ and 4.0 are shown in Figure.13, as functions of $T_{G G}$. In general, all of PAR are inversely proportional to $T_{G G}$. As compared to Isp in Fig.11, the larger PAR is, the greater Isp can be obtained. As same as Isp in Fig.11, the results of PAR also show the reversal behaviors between ethanol and $\mathrm{n}-\mathrm{C}_{12} \mathrm{H}_{26}$ around $T_{G G}=1300 \mathrm{~K}$ and $1500 \mathrm{~K}$, in Fig.13. This reversal behavior of PAR affects on that of Isp.

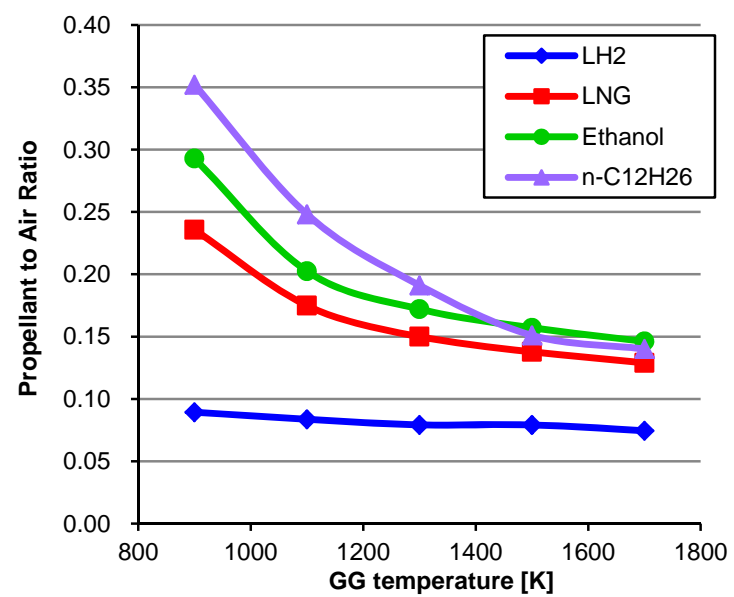

(a) $\pi_{\text {comp }}=2.5$

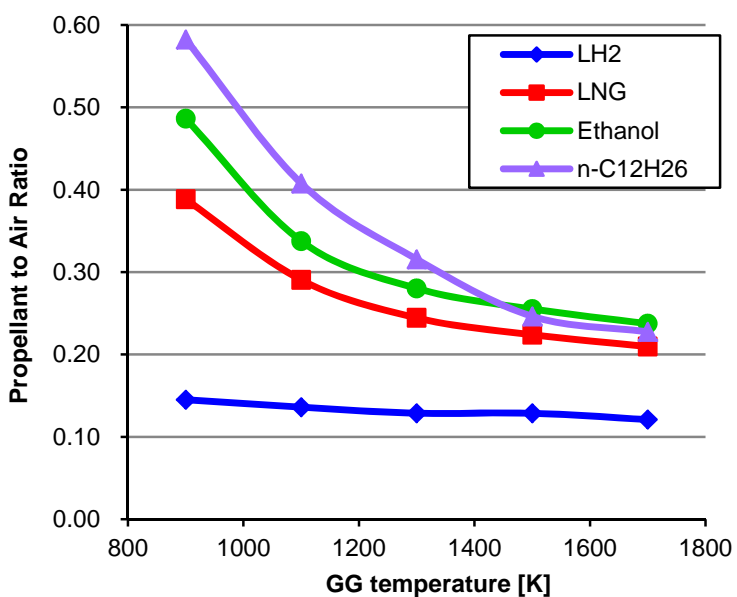

(b) $\pi_{\text {comp }}=4.0$

Figure 13 Propellant-to-Air Ratio for $\pi_{\text {comp }}=2.5$ and 4.0 
The chemical compositions of GG combustion gas are also investigated to clarify those reversal manners. Figure 14 indicates the mole fractions of GG combustion gases for $\pi_{\text {comp }}=2.5$. Chemical equilibrium calculations for GG combustion make clear that the main chemical species of those gases are $\mathrm{H}_{2}, \mathrm{CO}, \mathrm{CH}_{4}, \mathrm{H}_{2} \mathrm{O}$ and $\mathrm{CO}_{2}$ in the cases of hydrocarbon fuels, while those are composed of $\mathrm{H}_{2}$ and vapor for LH2. LH2 has the highest mole fraction of $\mathrm{H}_{2}$ in those 4 fuels and it is nearly equal to 80 percent or more. LNG has the second highest mole fraction of $\mathrm{H}_{2}$. The mole fraction of $\mathrm{H}_{2}$ for LH2 is decreased as $T_{G G}$ becomes higher. The presence of $\mathrm{H}_{2}$ in GG combustion gas contributes to high $C_{P}$, and therefore, plays a major role in reducing PAR.

(a) $\mathrm{LH} 2$

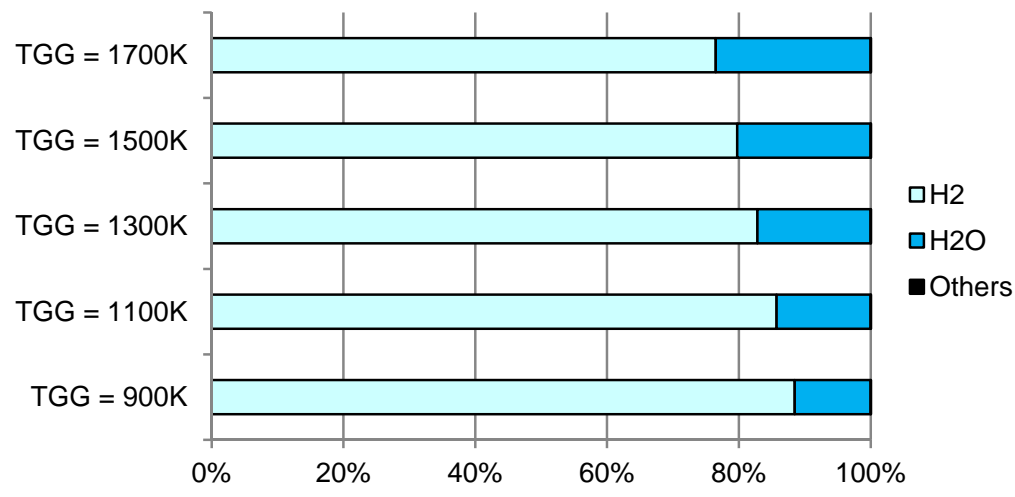

(b) LNG
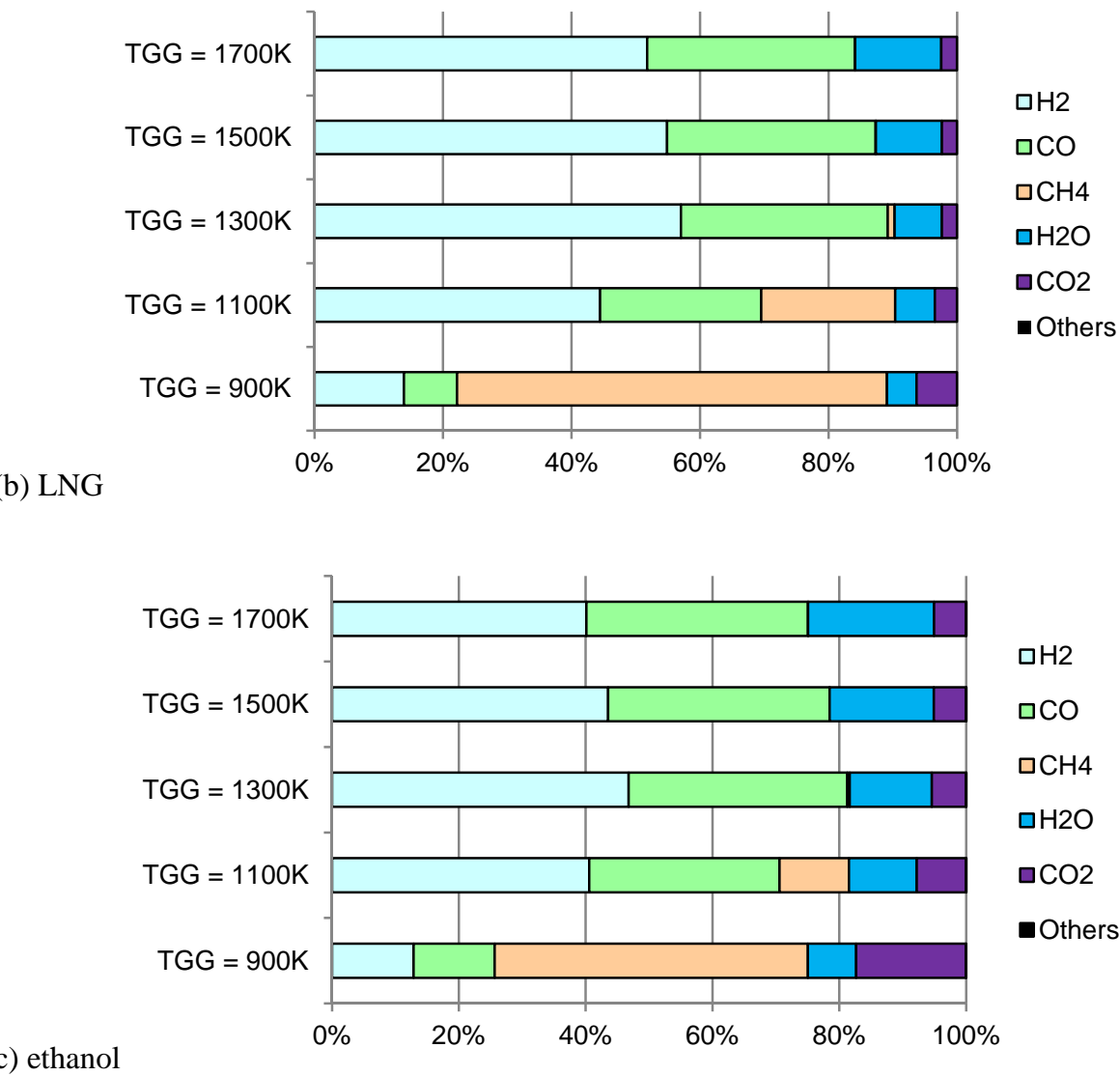


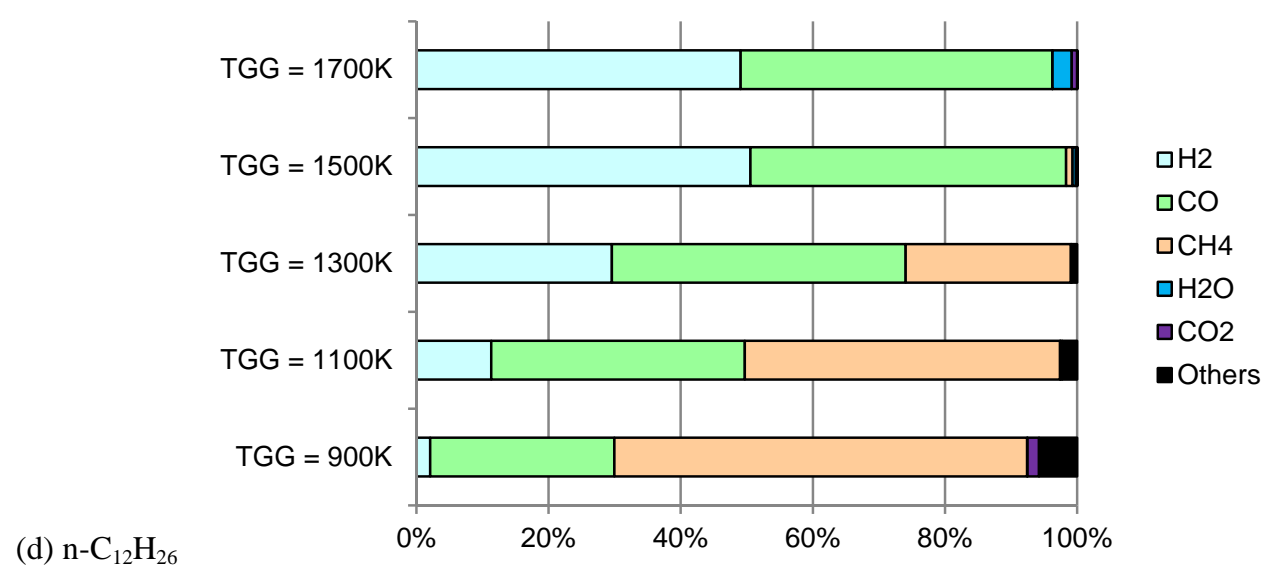

Figure 14 Chemical compositions of GG combustion gas for $\pi_{\text {comp }}=2.5$

In the cases of LNG and ethanol, the mole fraction of $\mathrm{H}_{2}$ at $T_{G G}=900 \mathrm{~K}$ is much lower than LH2, however, those are increased to about 40 percent at $T_{G G}=1100 \mathrm{~K}$ and reach to the maximum at $T_{G G}=1300 \mathrm{~K}$, which are equal to 57 and 46.7 percent for LNG and ethanol, respectively. The mole fractions of $\mathrm{CH}_{4}$ are 66.9 percent and 49.4 percent at $T_{G G}=900 \mathrm{~K}$ for LNG and ethanol, respectively. They are dramatically decreased as $T_{G G}$ increases and disappeared at $T_{G G}=1300 \mathrm{~K}$. The combustible gas species in GG gas are $\mathrm{H}_{2}$ and CO when $T_{G G}$ is more than $1300 \mathrm{~K}$. Total amounts of mole fractions of $\mathrm{H}_{2} \mathrm{O}$ and $\mathrm{CO}_{2}$ are about 10-15 percent for LNG and about 20 percent for ethanol. The amounts of species other than $\mathrm{H}_{2}, \mathrm{CO}, \mathrm{CH}_{4}, \mathrm{H}_{2} \mathrm{O}$ and $\mathrm{CO}_{2}$ are negligible.

For $n-\mathrm{C}_{12} \mathrm{H}_{26}$, the chemical species in the GG combustion gas are almost same with those for LNG and ethanol, however, the temperature dependencies of those chemical species are different from them. At $T_{G G}=900 \mathrm{~K}$, only 2.0 percent mole fraction of $\mathrm{H}_{2}$ is contained in GG combustion gas. The mole fraction of $\mathrm{H}_{2}$ remains to 11.3 percent at $T_{G G}=1100 \mathrm{~K}$ and 29.6 percent at $T_{G G}=1300 \mathrm{~K}$, which is lower than that of ethanol. However, it comes up to 50.6 percent at $T_{G G}=1500 \mathrm{~K}$. This $\mathrm{H}_{2}$ mole fraction exceeds that for ethanol at the same $T_{G G}$. The mole fraction of $\mathrm{CH}_{4}$ is 62.5 percent at $T_{G G}=900 \mathrm{~K}$ and reduce to $47.7,25.0$ and 0.01 percent at $T_{G G}=1100,1300$ and $1500 \mathrm{~K}$, respectively. At $T_{G G}=1500 \mathrm{~K}$, more than 98 mole percent of GG combustion gas are $\mathrm{H}_{2}$ and CO. Chemical species other than $\mathrm{H}_{2}$, $\mathrm{CH}_{4}, \mathrm{CO}, \mathrm{H}_{2} \mathrm{O}$ and $\mathrm{CO}_{2}$ are heavy hydrocarbon species, such as $\mathrm{C}_{2} \mathrm{H}_{4}, \mathrm{C}_{2} \mathrm{H}_{6}$, benzene, toluene, styrene, naphthalene and biphenyl. Total amount of those species are 5.7 percent by mole at $T_{G G}=900 \mathrm{~K}$ and 2.2 percent at $T_{G G}=1100 \mathrm{~K}$.

The reversal characteristics of Isp and PAR at $T_{G G}=1300 \mathrm{~K}$ in Fig.11 and 13 are caused by the change of chemical species distribution. Under $T_{G G}=1300 \mathrm{~K}$, the chemical species in GG combustion gas of n- $\mathrm{C}_{12} \mathrm{H}_{26}$ are mainly heavier molecules, $\mathrm{CO}$ and $\mathrm{CH}_{4}$, resulting of larger molecular weight of GG combustion gas. On the other hand, GG combustion gas of ethanol contains more $\mathrm{H}_{2}$ than $n-\mathrm{C}_{12} \mathrm{H}_{26}$, which means smaller molecular weight of GG combustion gas. GG combustion gas with low molecular weight provides turbine work more efficiently. Therefore, turbine work of ethanol can be extracted from GG combustion more efficiently than that of n- $\mathrm{C}_{12} \mathrm{H}_{26}$. If 
$T_{G G}$ is more than $1500 \mathrm{~K}$, GG combustion gas of $\mathrm{n}-\mathrm{C}_{12} \mathrm{H}_{26}$ has mainly $\mathrm{H}_{2}$ and CO. Especially, the presence of $\mathrm{H}_{2}$ in GG combustion gas of $n-\mathrm{C}_{12} \mathrm{H}_{26}$ is more than that of ethanol and can reduced its molecular weight, resulting of larger turbine work. That is the reason why Isp and PAR of ethanol are reversed with those of $n-\mathrm{C}_{12} \mathrm{H}_{26}$ at $T_{G G}=1300 \mathrm{~K}$.

Generally speaking, LH2 has the highest Isp and the largest specific thrust among 4 fuels. LNG has the second highest Isp. As previously mentioned, those two cryogenic fuels have low density and difficulties of handling. Considering of the drawbacks of cryogenic fuels, storable fuels are preferred. If storable fuel would be employed for GG-ATR engine, ethanol is considered to be more promising fuel than aviation kerosene because Isp of ethanol is superior to that of n- $\mathrm{C}_{12} \mathrm{H}_{26}$ when $T_{G G}$ is under $1300 \mathrm{~K} . T_{G G}$ should be lower than this temperature due to thermal limitation of turbine blade.

\subsection{Thermal Efficiency of GG-ATR engine}

Besides of specific thrust and Isp, thermal efficiency is also the parameter to evaluate propulsion performance. The thermal efficiency of GG-ATR engine is defined as equation (9).

$$
\eta_{t h}=\frac{\dot{m}_{\text {Air }}\left[(1+f) \frac{V_{e x t}^{2}}{2}-\frac{V^{2}}{2}\right]}{\dot{m}_{\text {fuel }} h}=\frac{(1+f) \frac{V_{e x t}^{2}}{2}-\frac{V^{2}}{2}}{\frac{f}{1+r_{\text {OF }}} h}
$$

where $h$ and $r_{O F}$ are specific heat release of fuel and oxidizer to fuel ratio at gas generator, respectively. $f$ is PAR defined in eq.(3). This definition of thermal efficiency is similar to that of a conventional turbojet engine, however, PAR in eq.(9) includes the oxidizer flow rate. The denominator of the equation (9) indicates specific heat release of fuel. As mentioned previously, fuel of GG-ATR engine burns in two stages. At the first stage, the fuel is burnt in the gas generator and its thermal energy is utilized to drive the turbine. Secondary, the rest of fuel is burnt with air at the ram combustor. For both combustion, the fuel reacts with oxygen, therefore, $h$ can be evaluated as the specific heat release of fuel and oxygen combustion.

Figure 15 indicates thermal efficiency of GG-ATR engine at sea level static condition for $\pi_{\text {comp }}=2.5$ and 4.0 , respectively. The rotational speed of the engine is the on-design condition speed. The higher $T_{G G}$ condition, the greater thermal efficiency can be achieved. In the case of $\pi_{\text {comp }}=2.5$, Ethanol has the largest thermal efficiency and LNG has the second largest among those 4 fuels for $T_{G G}$ more than $1100 \mathrm{~K}$. However, for LNG, ethanol and n- $\mathrm{C}_{12} \mathrm{H}_{26}$, thermal efficiency is significantly decreased at $T_{G G}=900 \mathrm{~K}$. Figure 16 shows $\mathrm{H}_{2}$ and CO mole fraction in the ram combustor gas. If the ram combustion is done at fuel rich condition, mole fractions of those species increase. Existences of $\mathrm{H}_{2}$ and $\mathrm{CO}$ in the ram combustor gas indicate that unburned fuel is remained. Those 
unburned fuel make thermal efficiency reduced. Generally, $\mathrm{H}_{2}$ and $\mathrm{CO}$ mole fractions for $\pi_{\text {comp }}=4.0$ are greater than those for $\pi_{\text {comp }}=2.5$. The result in Fig.15 can explain why the reason the highest thermal efficiency of ethanol as indicated in Fig.15. For $T_{G G}$ more than $1100 \mathrm{~K}, \mathrm{H}_{2}$ and $\mathrm{CO}$ mole fractions for ethanol are less than those for other 3 fuels.

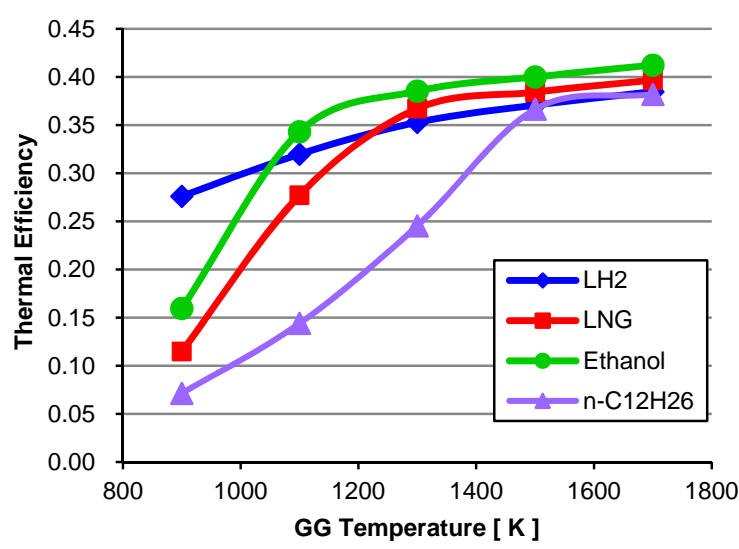

a) $\pi_{\text {comp }}=2.5$

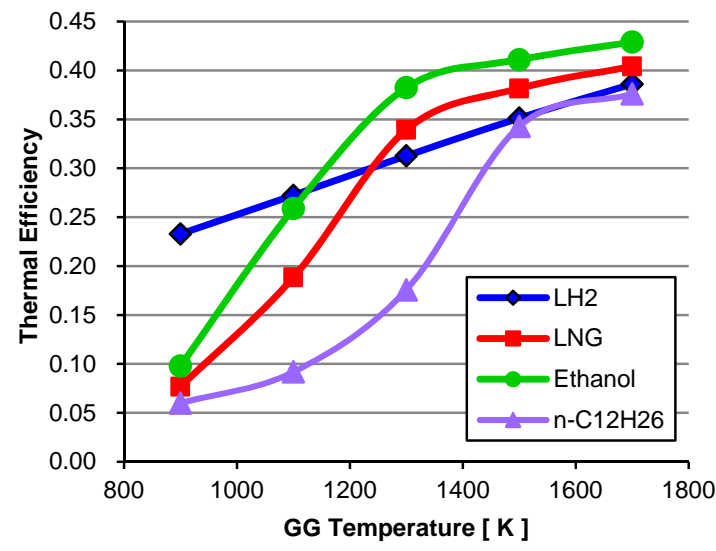

b) $\pi_{\text {comp }}=4.0$

Figure 15 Thermal efficiency of GG-ATR engine for $\pi_{\text {comp }}=2.5$ and 4.0.

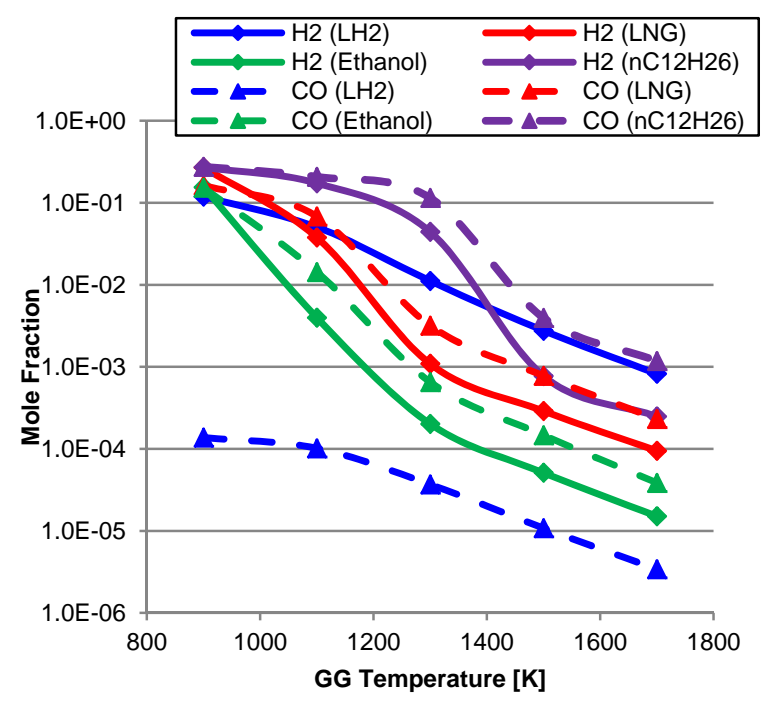

a) $\pi_{\text {comp }}=2.5$

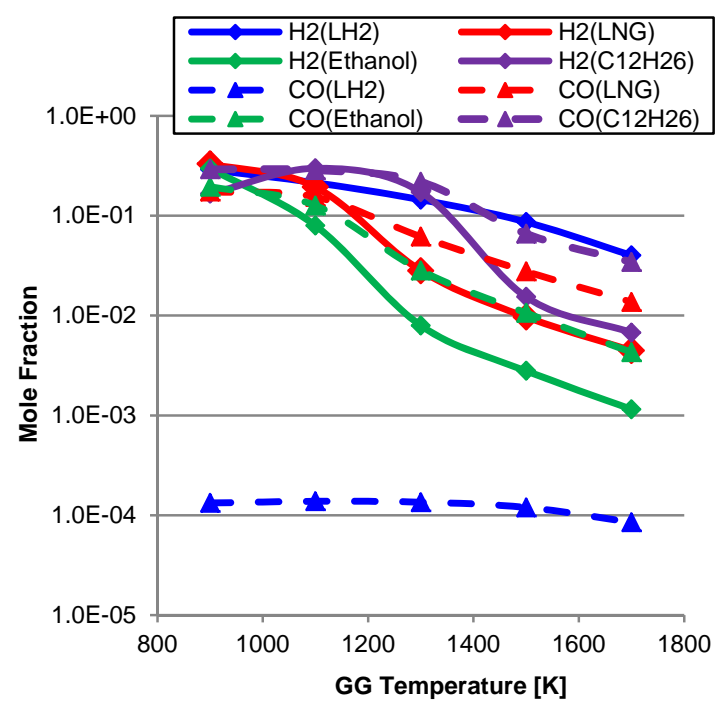

b) $\pi_{\text {comp }}=4.0$

Figure 16 Mole Fraction of $\mathrm{H}_{2}$ and $\mathrm{CO}$ in Ram Combustor for $\pi_{\text {comp }}=2.5$ and 4.0.

\subsection{Off-Design Performances of GG-ATR engine}

The previous sections discuss only analytical results in on-design condition and can indicate the ethanol superiority to $n-\mathrm{C}_{12} \mathrm{H}_{26}$ for lower $T_{G G}$ condition. However, the advantage of ethanol fuel should be verified in off-design conditions. In the present section, $\pi_{\text {comp }}$ and $T_{G G}$ are fixed to 2.5 and $1100 \mathrm{~K}$, respectively. Those are 
assumed to be actual conditions of $\pi_{\text {comp }}$ and $T_{G G}$ for the author's GG-ATR engine. Figure 17 and 18 show the specific thrust and Isp as functions of specific actual rotational speed, $N_{S}$, at sea level static condition, respectively. The specific thrust of ethanol is more rapidly decreased than other 3 fuels. As $N_{s}$ decrease less than 0.8 , Isp of ethanol is reduced and nearly equal to that of $n-\mathrm{C}_{12} \mathrm{H}_{26}$. The superiority of ethanol to $n-\mathrm{C}_{12} \mathrm{H}_{26}$ is valid only at $N_{S}$ greater than 0.85 .

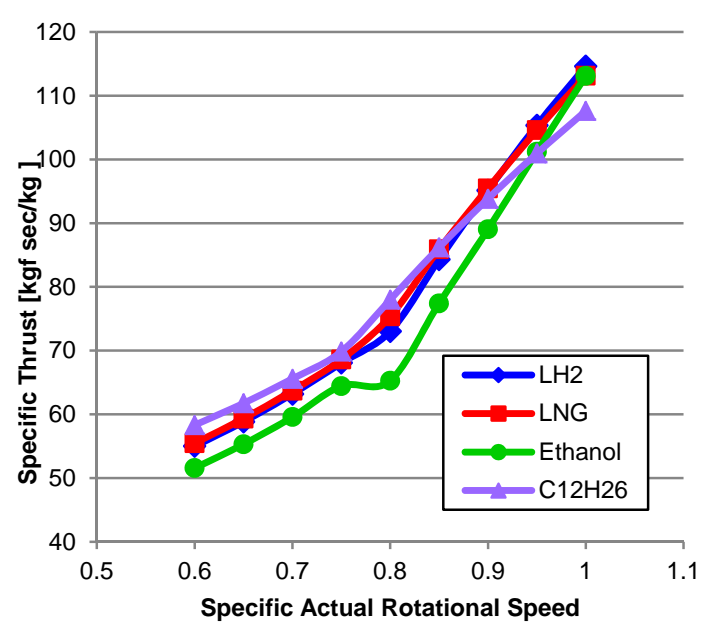

Figure 17 Specific Thrusts as function of $N_{S}$

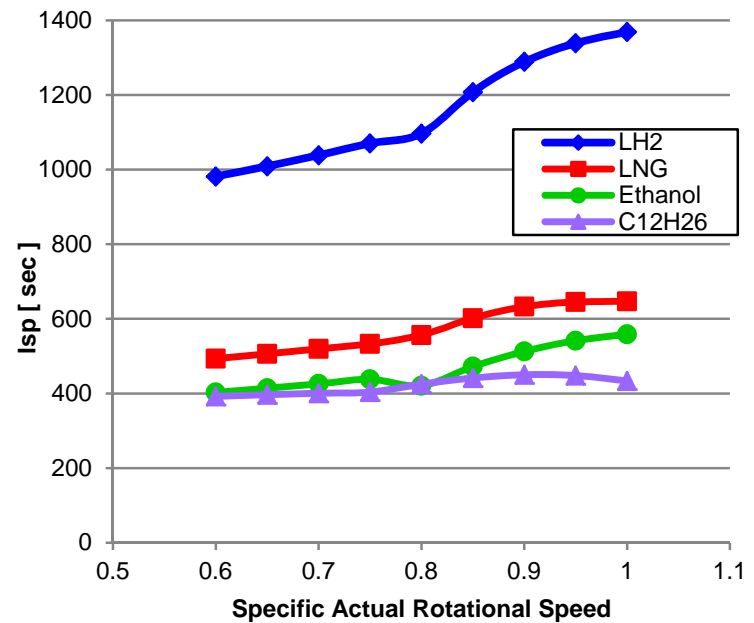

Figure 18 Isp as function of $N_{S}$

Figure 19 shows the ram combustor temperature, $T_{\text {ram }}$, at sea level static condition as function of $N_{S}$. $T_{\text {ram }}$ of ethanol is monotonically decreased as $N_{S}$ increases, while, that of $n-\mathrm{C}_{12} \mathrm{H}_{26}$ is monotonically increased. As discussed about $T_{\text {ram }}$ in Fig.10, ram combustion of n- $\mathrm{C}_{12} \mathrm{H}_{26}$ for $N_{S}=1.0$ is fuel-rich condition. As $N_{S}$ is reduced, the compressor pressure ratio, $\pi_{\text {comp }}$, is decreased. This situation leads the ram combustion of $n-\mathrm{C}_{12} \mathrm{H}_{26}$ from fuel-rich to stoichiometric condition. On the other hand, the ram combustion of ethanol for $N_{S}=1.0$ is fuel lean condition. The reduction of $N_{S}$ lets the ram combustion to be in further fuel lean condition. Those are the reason that the superiority of ethanol to n- $\mathrm{C}_{12} \mathrm{H}_{26}$ is disappeared for $N_{S}$ less than 0.8 .

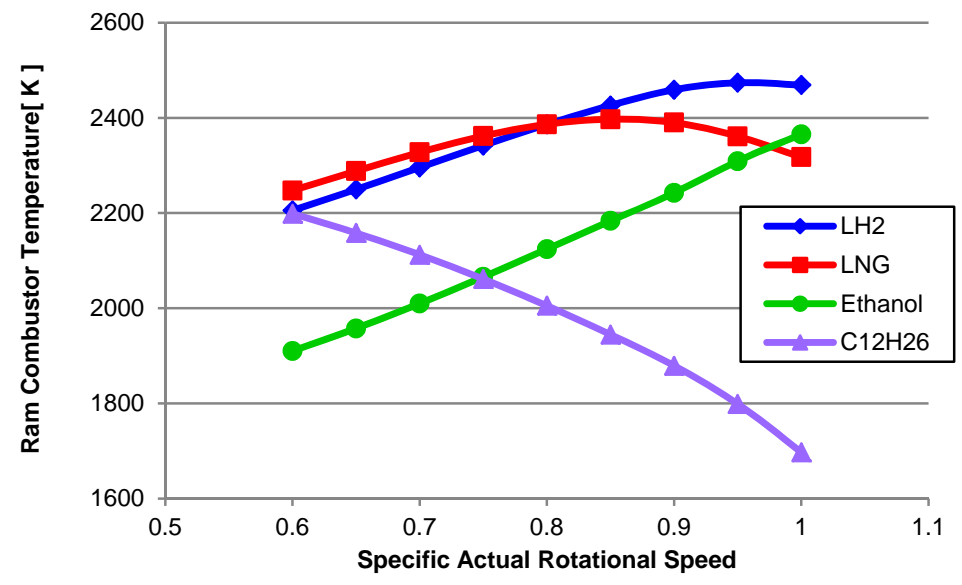

Figure 19 Ram Combustor Temperature as function of $N_{S}$ at Sea level static condition 
To investigate flight capability of GG-ATR engine, it is necessary to evaluate its performance along the flight trajectory. Figure 20 shows the expected flight trajectory of the supersonic UAV at Muroran Institute of Technology. This UAV is planning to take off at Mach 0.3 and travel along the $25 \mathrm{kPa}$ constant dynamic pressure trajectory in more than Mach 0.7 .

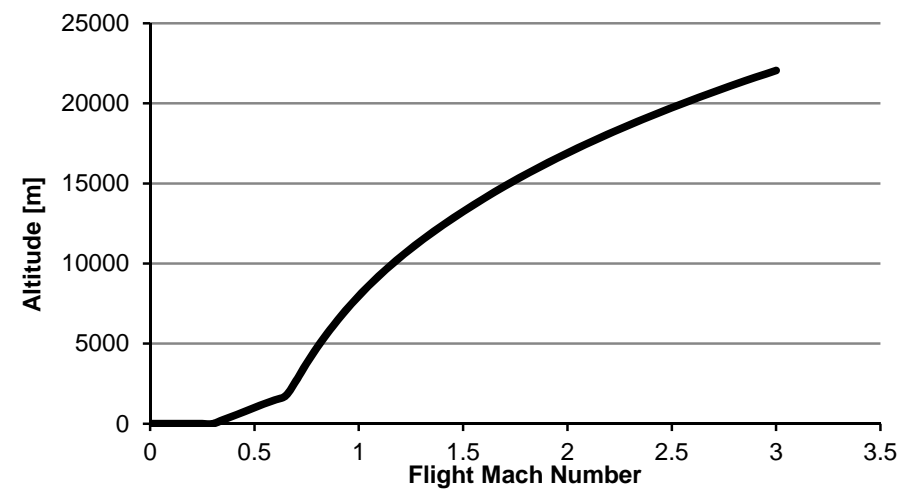

Figure 20 Expected Flight Trajectory of Supersonic UAV at Muroran Inst. of Tech.

The specific thrust and Isp along this trajectory are shown in Figure 21 and 22, respectively. In those figures, the actual rotational speed, $N$, keeps to on-design condition speed along this trajectory. $\mathrm{O} / \mathrm{F}$ ratio at the gas generator is also constant because $T_{G G}$ should keep constant. $\pi_{\text {comp }}$ and $T_{G G}$ are 2.5 and $1100 \mathrm{~K}$ at Mach 0.0 , respectively, however, $\pi_{\text {comp }}$ is varied with the flight condition. Both specific thrust and Isp are maximum from Mach 1.5 to 2.0. The magnitude relations of specific thrust and Isp among those 4 fuels are almost invariant along the flight trajectory.

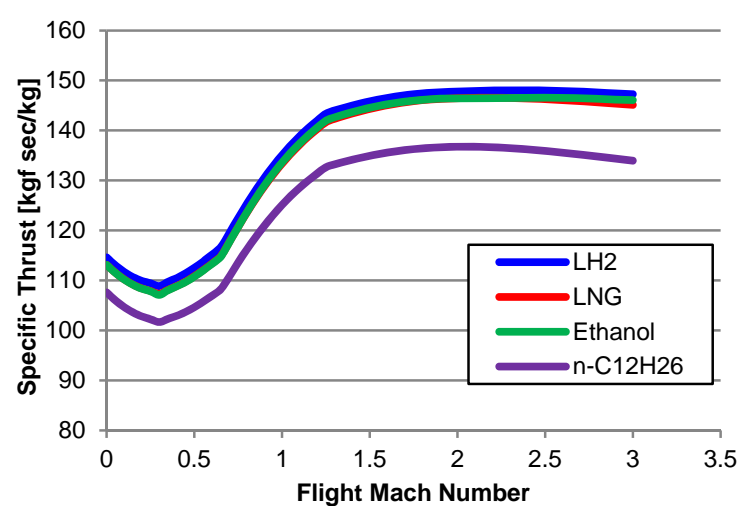

Figure 21 Specific Thrust along Flight Trajectory

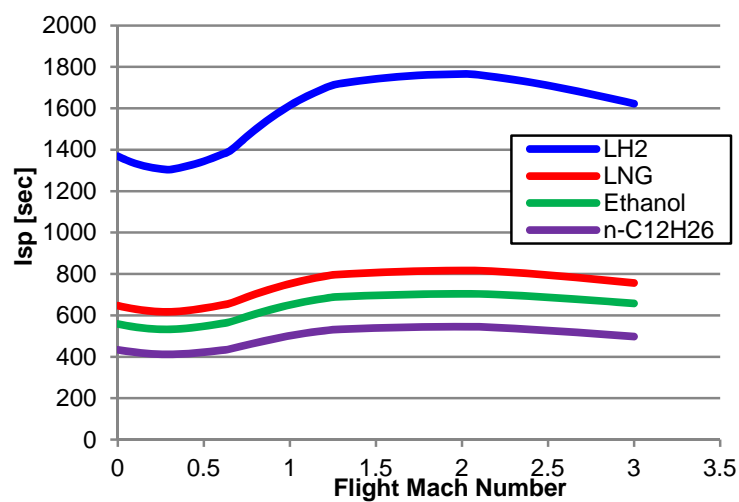

Figure 22 Isp along Flight Trajectory 


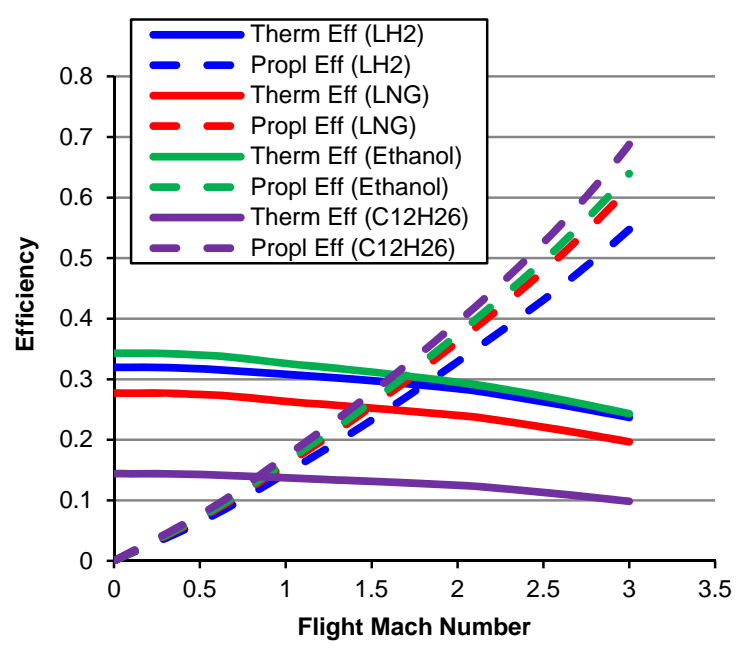

Figure 23 Thermal and Propulsive Efficiencies

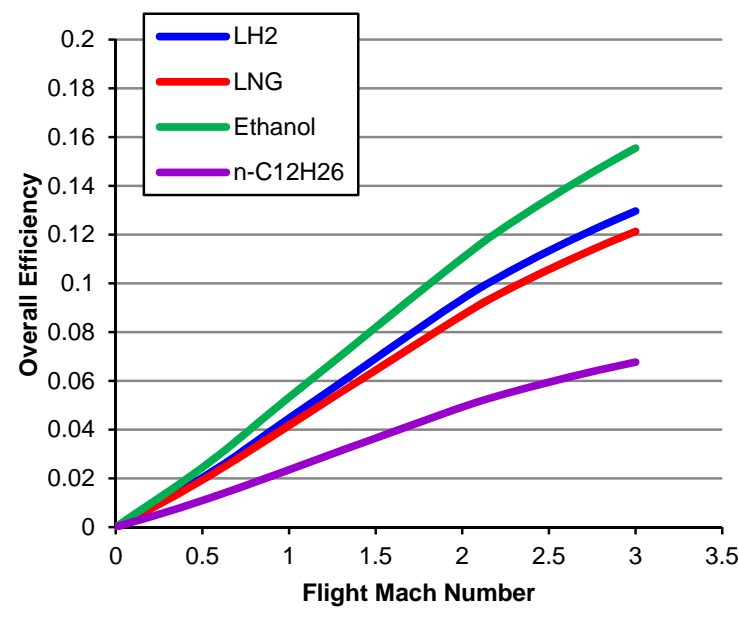

Figure 24 Overall Efficiency along Flight Trajectory

along Flight Trajectory

Finally, thermal, propulsive and overall efficiencies of GG-ATR engine along this flight trajectory are shown in Figure 23 and 24. As shown in Fig.15, Figure 23 also shows that thermal efficiency of $n-\mathrm{C}_{12} \mathrm{H}_{26}$ is significantly lower than other 3 fuels for $\pi_{\text {comp }}=2.5$ and $T_{G G}=1100 \mathrm{~K}$. On the other hand, ethanol has the largest thermal efficiency among those 4 fuels as well as Fig.15. The thermal efficiencies in Fig.23 largely affects on the overall efficiencies in Fig.24. Thus, ethanol has the largest overall efficiency among those 4 fuels. Those results also imply the superiority of ethanol fuel to $n-\mathrm{C}_{12} \mathrm{H}_{26}$ for GG-ATR engine fuel.

\section{Conclusion}

Propulsion performance analyses are conducted for GG-ATR engine to investigate preferable propellant. In the present study, LH2, LNG, ethanol and $n-\mathrm{C}_{12} \mathrm{H}_{26}$ are the object of investigation while LOX is specified to the oxidizer. The results are summarized as follow.

1. Specific thrusts are roughly proportional to the ram combustor temperature, $T_{\text {ram }}$. In the case of $\pi_{\text {comp }}=2.5$, the maximum specific thrust of ethanol exists at $T_{G G}=1100 \mathrm{~K}$ and that for $\mathrm{n}-\mathrm{C}_{12} \mathrm{H}_{26}$ exists at $T_{G G}=1300 \mathrm{~K}$, where stoichiometric combustion is considered to be occurred. $T_{G G}$ should be less than $1100 \mathrm{~K}$, because of thermal limitation of turbine blade. In such $T_{G G}$ condition, ethanol has larger specific thrust than n- $\mathrm{C}_{12} \mathrm{H}_{26}$.

2. LH2 has the highest Isp among those 4 fuels and LNG has the second highest one. For storable fuels, ethanol has higher Isp than $\mathrm{n}-\mathrm{C}_{12} \mathrm{H}_{26}$ for $T_{G G}$ less than $1300 \mathrm{~K}$, although ethanol has only two-thirds of specific heat release of $n-\mathrm{C}_{12} \mathrm{H}_{26}$. Ethanol is storable and easy handling fuel. $T_{G G}$ should be less than $1100 \mathrm{~K}$, due to thermal limitation of turbine blade. Thus, ethanol is more promising fuel than aviation kerosene for GG-ATR engine from the viewpoint of practical application. Moreover, the thermal efficiency of ethanol fuel is the greatest among those 4 fuels in on-design point condition. 
3. At $T_{G G}=1500 \mathrm{~K}$, main chemical species of GG combustion gas for $\mathrm{n}-\mathrm{C}_{12} \mathrm{H}_{26}$ are $\mathrm{H}_{2}$ and $\mathrm{CO}$. $\mathrm{H}_{2}$ mole fraction of it reaches to more than 50 percent, which is higher than that for ethanol at the same $T_{G G}$ condition. High $\mathrm{H}_{2}$ concentration in GG combustion gas plays role in reducing its molecular weight and increase Isp. However, at $T_{G G}=1100 \mathrm{~K}$, GG combustion gas for $\mathrm{n}-\mathrm{C}_{12} \mathrm{H}_{26}$ are mainly composed of $\mathrm{CH}_{4}$ and CO. $\mathrm{H}_{2}$ mole fraction contains only 11.3 percent in GG combustion gas, while those for ethanol are more than 40 percent. These facts indicate that PAR of ethanol is lower than that of $n-\mathrm{C}_{12} \mathrm{H}_{26}$, resulting of higher Isp of ethanol.

4. The off-design analysis reveals that Isp of ethanol at sea-level static condition is nearly equal to that of n- $\mathrm{C}_{12} \mathrm{H}_{26}$ when specific actual rotational speed, $N_{S}$, is less than 0.8 . In on-design point condition, ram combustion of $n-\mathrm{C}_{12} \mathrm{H}_{26}$ is highly fuel rich condition, however, it becomes to stoichiometric combustion for low $N_{S}$ condition, resulting of improvement of Isp. On the other hand, in the flight condition, Isp of ethanol fueled GG-ATR engine is superior to that of $n-\mathrm{C}_{12} \mathrm{H}_{26}$ along the expected flight trajectory, if $N_{S}=1.0$. In addition, overall efficiency of ethanol fueled GG-ATR engine is the greatest among 4 fuels along this flight trajectory. This fact also indicates the superiority of ethanol to $n-\mathrm{C}_{12} \mathrm{H}_{26}$ for GG-ATR engine application.

\section{Conflict of interest statement}

The authors declare no conflict of interest.

\section{Reference}

[1] Tanatsugu, N. "Development study on air turboramjet”, Developments in High-Speed-Vehicle Propulsion Systems, (1996), Progress in Astronautics and Aeronautics Vol.165

[2] Snyder, C.A. “A Parametric Study of a Gas-Generator AirTurbo Rocket (ATR)” NASA TM 88808 (1986).

[3] Bussi, G., Colasurdo, G. and Pastrone, D., ”Analysis of Air-Turborocket Performance”, Journal of Propulsion and Power Vol.11, No.5 (1995), pp.950-954.

[4] Christensen, K. “Air Turborocket/Vehicle Performance Comparison”, Journal of Propulsion and Power Vol.15, No.5 (1999), pp.706-712.

[5] Hasegawa, H., Kitahara, K. and Inukai, Y. ”Compact and High Thrust AirTurbo Ram Engine” Journal of the Japan Society for Aeronautical and Space Sciences, Vol.50, No.582. (2002) ( in Japanese )

[6] Christensen, K. “Comparison of Methods for Calculating Turbine Work in the Air Turborocket”, Journal of Propulsion and Power Vol.17, No.2 (2001), pp.256-261.

[7] Sullerey, R.K., Pradeep, A.M. and Kedia, M,’Performance Comparison of Air Turborocket Engine with Different Fuel Systems” AIAA-Paper 2003-4417

[8] Mizobata, K., Minato, R., Higuchi, K., Ueba, M., Takagi, S., Nakata, D., Higashino, K., and Tanatsugu, N., “Development of a Small-scale Supersonic Flight Experiment Vehicle as a Flying Test Bed for Future 
Space Transportation Research,” ISTS Special Issue: Transactions of JSASS, Aerospace Technology Japan, Vol.12, No. ISTS 29, pp. Po 3 1-Po3 10, 2014.

[9] Gordon, S. and McBride, B. J., “Computer Program for Calculation of Complex Chemical Equilibrium Compositions, Rocket Performance, Incident and Reflected Shock and Chapman-Jouguet Detonations”, NASA SP-273. (1971).

[10] “Liquid Rocket Engine Turbine”, NASA SP-8110 (1974).

[11] Mattingly, J.D. “Element of Propulsion” AIAA Educational Series (2006). pp.459

[12] Lilly, J. S., Hecht, S. E., Kirkham, B. G. and Eadon, C.A. "Experimental Evaluation of aa Air Turbo Ramjet”, AIAA Paper 94-3386.

[13] McAulay, J.E. and Abdelwabab "Experimental Evaluation of a TF30-P-3 Turbofan Engine in an Altitude Facility: Afterburner Performance and Engine-Afterburner Operating Limits”, NASA TN D-6839 (1972).

[14] Reference.11 in pp278-283, and pp.381-387

Vitae

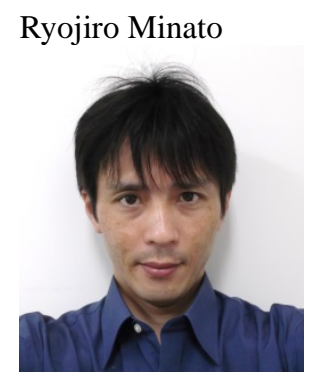

Assistant Professor in Muroran Institute of Technology Ryojiro Minato was received Doctor of Engineering (Aerospace Engineering) from Tohoku University and moved to Muroran Institute of Technology and currently engaged to research and development of subscale gas generator cycle air turbo ramjet engine for supersonic unmanned aerial vehicle engine. 